\title{
Novel Binders and Methods for Agglomeration of Ore
}

Semiannual Technical Progress Report

Reporting Period Start Date: April 2006

Reporting Period End Date: September 2006

Authors:

PI: S. K. Kawatra

T. C. Eisele

K. A. Lewandowski

J. A. Gurtler

Report Issued October 2006

DOE award \# DE-FC26-03NT41924

Budget Period 2

Submitting Organization:

Michigan Technological University

Department of Chemical Engineering

1400 Townsend Dr

Houghton, MI 49931 


\section{Disclaimer}

This report was prepared as an account of work sponsored by an agency of the United States Government. Neither the United States Government nor any agency thereof, nor any of their employees, makes any warranty, express or implied, or assumes any legal liability or responsibility for the accuracy, completeness, or usefulness of any information, apparatus, product, or process disclosed, or represents that its use would not infringe privately owned rights. Reference herein to any specific commercial product, process, or service by trade name, trademark, manufacturer, or otherwise does not necessarily constitute or imply its endorsement, recommendation, or favoring by the United States Government or any agency thereof. The views and opinions of authors expressed herein do not necessarily state or reflect those of the United States Government or any agency thereof. 


\begin{abstract}
Heap leaching is one of the methods being used to recover metal from low grade ore deposits. The main problem faced during heap leaching is the migration of fine grained particles through the heap, forming impermeable beds which result in poor solution flow. The poor solution flow leads to less contact between the leach solution and the ore, resulting in low recovery rates. Agglomeration of ore into coarse, porous masses prevents fine particles from migrating and clogging the spaces and channels between the larger ore particles. Currently, there is one facility in the United States which uses agglomeration. This operation agglomerates their ore using leach solution (raffinate), but is still experiencing undesirable metal recovery from the heaps due to agglomerate breakdown. The use of a binder, in addition to the leach solution, during agglomeration would help to produce stronger agglomerates that did not break down during processing. However, there are no known binders that will work satisfactorily in the acidic environment of a heap, at a reasonable cost. As a result, operators of many facilities see a large loss of process efficiency due to their inability to take advantage of agglomeration.

Increasing copper recovery in heap leaching by the use of binders and agglomeration would result in a significant decrease in the amount of energy consumed. Assuming that $70 \%$ of all the leaching heaps would convert to using agglomeration technology, as much as $1.64 * 10^{12}$ BTU per year would be able to be saved if a $25 \%$ increase in copper recovery was experienced, which is equivalent to saving approximately $18 \%$ of the energy currently being used in leaching heaps. For every week a leach cycle was decreased, a savings of as much as $1.23 * 10^{11}$ BTU per week would result. This project has identified several acid-resistant binders and agglomeration procedures. These binders and experimental procedures will be able to be used for use in improving the energy efficiency of heap leaching.
\end{abstract}




\section{Table of Contents}

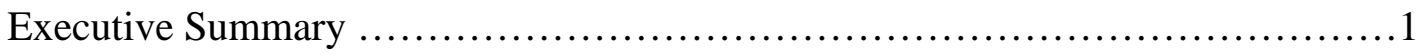

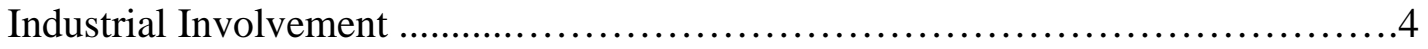

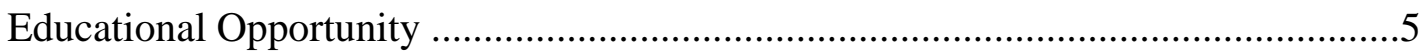

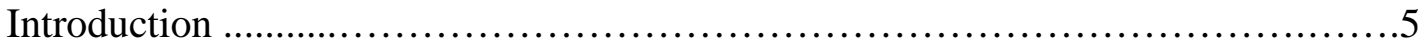

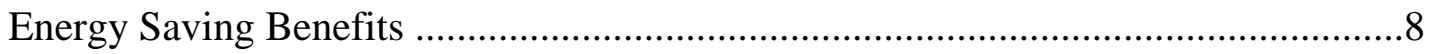

Binder Evaluation............................................................

Economic Analysis.....................................................35

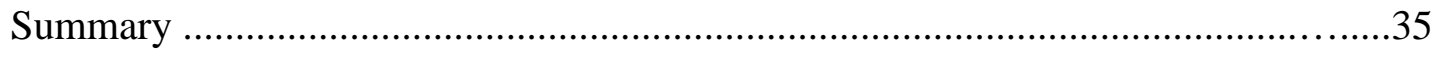

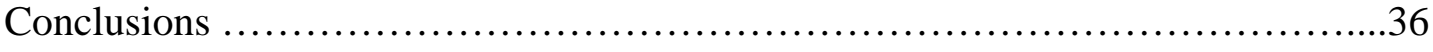

References..................................................................

\section{List of Figures}

Figure 1: Copper Heap Leaching Process ......................................................6

Figure 2: Ideal Homogenous Ore Bed Size Distribution .....................................

Figure 3: Actual Heterogeneous Ore Bed Size Distribution..................................

Figure 4: Agglomeration Mechanism - Solid Bridges .......................................

Figure 5: Agglomeration Mechanism - Adhesion and Cohesion Forces ...........9

Figure 6: Agglomeration Mechanism - Liquid Bridges ...................... 10

Figure 7: Agglomeration Mechanism - Attraction Forces ....................... 10

Figure 8: Agglomeration Mechanism - Interlocking Bonds ................................11

Figure 9: Energy Consumption Comparison ......................................................14 
Figure 10: Cumulative Energy Savings …………………....................................15

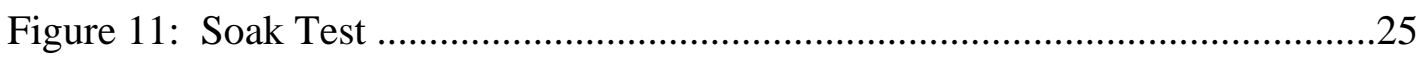

Figure 12: Visual Deterioration of Agglomerates in Soak Test ................................27

Figure 13: Visual Deterioration of Agglomerates after Soak Test ............................27

Figure 14: Fines Migration Results in Soak Test...................................................28

Figure 15: Effect of Cure Time on Agglomerate Strength ........................................29

Figure 16: Flooded Test Columns.........................................................................31

Figure 17: Schematic of Flooded Test Columns........................................................32

Figure 18: Ratio of Fines in Flooded Column Test ……………………………......33

Figure 19: Change in Ore Bulk Density .................................................................34

Figure 20: Hydraulic Conductivity ..........................................................................35

Figure 21: Hydraulic Conductivity Evaluation for Polyvinyl Acetate .......................36

Figure 22: Bulk Density Evaluation for Polyvinyl Acetate......................................36

Figure 23: Hydraulic Conductivity Evaluation for Polyacrylamide ..........................36

Figure 24: Bulk Density Evaluation for Polyacrylamide............................................36

Figure 25: Hydraulic Conductivity Evaluation for Waste Treatment Additive.........36

Figure 26: Bulk Density Evaluation for Waste Treatment Additive ..........................36

Figure 27: Hydraulic Conductivity Evaluation for Tall Oil Pitch ..............................37

Figure 28: Bulk Density Evaluation for Tall Oil Pitch.............................................37

Figure 29: Long Term Leach Columns..................................................................38

Figure 30: Schematic of Long Term Leach Columns................................................39

Figure 31: Cumulative Copper Recovery …………………………………….......40

Figure 32: Change in Oxidation/Reduction Potential .................................................41 
Figure 33: Total Change in Bulk Density Long-Term Leach Columns ..................42

Figure 34: Bulk Density from Compression Testing for Raffinate .........................43

Figure 35: Ponding Effects from Compression Testing .....................................45

Figure 36: Bulk Density for all Compression Tests..........................................46

Figure 37: Hydraulic Conductivity for all Compression Tests ..............................47

\section{List of Tables}

Table 1: Energy Consumption at Phelps Dodge in 2002 ........................................ 12

Table 2: Energy Savings with Percent Increase in Recovery ................................13

Table 3: Binders Tested in Previous Studies .......................................................17

Table 4: Test Conditions used on Polymer at CIPIMM ........................................24

Table 5: Fines Migration Results in Soak Test.................................................28

Table 6: Effect of Cure Time on Agglomerate Strength.......................................29 


\section{Executive Summary}

The high grade ores which were once easily mined have become depleted. The lower grade ores, such as precious metal or copper ore, are able to be recovered by heap leaching. This is a method that is used to recover lower grade ores in a reasonable amount of time, at low capital, and with low operating costs (Eisele et al., 1984; Dixon, 2003; McClelland, 1985; Weir, 1984).

In secondary sulfide copper heap leaching operations, such as chalcocite $\left(\mathrm{Cu}_{2} \mathrm{~S}\right)$, the liberation of copper from the mineral was done through a two-step chemical reaction with ferric iron $\left(\mathrm{Fe}^{3+}\right)$. The ferric iron $\left(\mathrm{Fe}^{3+}\right)$ was then regenerated from ferrous iron $\left(\mathrm{Fe}^{2+}\right)$ using a bacterial reaction which consumes oxygen and acid. These reactions illustrate that the heap leaching of copper sulfide minerals required adequate permeability to allow for solution, with dissolved iron, to maintain access to the ore particles. They also require easy flow of air to provide oxygen for bacterial growth.

However, the copper recovery rates in these copper heap leaching operations are still not as high as desired. To liberate the copper within the ore, it is necessary for the ore to be ground to finer particle sizes. The finer-grained ore is harder to handle and requires a lot more energy to be used. When placed in a heap the fine material migrates downward and clogs the spaces between the larger ore particles. It is the migration of fines that leads to poor permeability, the main problem in heap leaching. Poor permeability limits the available contact which can be made between the ore, air, and leach solution. Limited contact between the ore, air, and leach solution slows the speed at which the chemical reactions take place, and results in not being able to achieve the desired copper recovery rates.

Agglomerating the material into pellets, similar masses, or particles that are durable enough to be handled, is one of the solutions to dealing with these fine mineral concentrates. The agglomerated particles would help to increase permeability in the heap by binding the fine particles to the larger particles. This would limit the amount of free fine particles, which may clog the spaces between the larger particles limiting solution flow.

There is one copper heap leaching facility in the United States which currently uses agglomeration; however, they agglomerate with only raffinate, the leach solution. This facility is still observing copper outputs below the desired recovery rate. This is due to the rapid breakdown of the agglomerates. Deterioration of agglomerates results in the release of fine material which clogs flow channels in the ore bed, leaving areas in the heap void of the necessary reagents to dissolve the copper. Thus, resulting in lower recoveries than what is expected. Increasing the permeability in the heaps would allow for the leach solution to come in contact with all the ore, allowing the desired extraction rates to be achieved.

Preventing agglomerate breakdown and limiting the migration of fines by the utilization of cost effective binders in the agglomeration step would enhance the overall recovery of 
the heap. Increasing copper recovery in heap leaching by the use of binders and agglomeration would result in a significant decrease in the amount of energy consumed. Assuming that $70 \%$ of all the leaching heaps would convert to using agglomeration technology, as much as $1.64 * 10^{12}$ BTU per year would be able to be saved if a $25 \%$ increase in copper recovery was experienced. This is the equivalent to saving approximately $18 \%$ of the energy currently being used in leaching heaps. Even if the copper recovery may not be able to be increased, the desired recovery may be achieved but with a shortened leach period. Shortening the leach cycle of a heap leach one week allows for total energy savings of $1.23 * 10^{11}$ BTU/Week assuming $70 \%$ of the leach heaps implements the technology. Achieving increased copper recovery along with a decrease in leach time will only amplify the energy saving results expected from either one of these alone.

To increase recovery, the use of a binder would help the problem by causing fine material to adhere to the coarser material. The result would be an increase in the permeability of the heap, which would allow for better flow of the air and leach solution through the heap. However, copper leaching requires a high use of acid solutions which decrease the $\mathrm{pH}$ of the heap to very acidic conditions. Most agglomeration binders which are used successfully in other operations, such as Portland cement and lime, require a more neutral or alkaline $\mathrm{pH}$. These cement-type binders dissolve readily in acid, and are completely ineffective in an acidic leaching environment. Acid-resistant binders are needed for these copper heap leaching operations which will not breakdown in the acidic conditions, allowing access of air and leach solutions to reach the ore particles.

This project has explored the development of a binder for mineral agglomeration that allows for increased processing efficiency. A variety of binders were initially chosen based on theoretical considerations and on past experience. However, there were no standard procedures to test the performance of a binder for agglomeration in heap leaching. An agglomeration procedure was developed which could be used to evaluate the performance of the chosen binders. The first concern was to whether the binders would be able to withstand the acidic conditions that would be experienced in a heap. The soak test was developed as a quick and easy test to determine which types of binders would or would not be able to withstand the acidic environment of a heap. The results narrowed down the extensive field of possible binders. They indicated that inorganic and organic binders all deteriorated under acidic conditions. Polymer binders, mainly nonionic and slightly cationic binders, are able to produce the greatest agglomerate strength, indicated by possessing the least amount of breakdown under acidic conditions.

After narrowing down the field of possible binders, it was necessary to determine whether the polymer binders would interfere with the solution and air flow through the ore bed. There was a possibility the addition of a binder may raise the viscosity of the solution enough to where the leach solution would not be able to flow freely. No standard testing procedures to do this were in place. A flooded column experiment was developed to test the degree of void space between ore particles and the ease of solution flow with the use of the selected binders. Both of these factors allowed a quantitative measurement to be made of the permeability of the ore to the leach solution as a function of time. 
Results from the flooded column tests proved that the polymer binders were able to increase the strength of the agglomerates. This was shown by a small change in the bulk density of the ore bed, which indicated void spaces were maintained with the use of these binders. Agglomerating with polymeric binders also helped to increase solution flow when compared to using raffinate alone as a binder. These factors are important, as they aid in the availability for the solution to come in contact with the ore, and lead to increased metal recovery rates.

After several binders had been determined, which were able to withstand an acidic environment and helped to increase the ease of solution flow, while maintaining void space, it was crucial to determine if these binders would adversely affect copper recovery. To analyze the effect of the use of the binders on copper recovery and bacterial growth, the long-term leach column was developed. These columns were as close of a simulation to an actual industrial heap as was able to be performed at the time. Six longterm leach columns have been completed at Michigan Technological University (MTU). The use of binders has not shown any negative effects towards copper recovery or bacterial growth. These long-term leach column experiments were also duplicated at a copper heap leach facility in Arizona.

The drawback to this test is that these columns are only able to reproduce what is occurring within the top 5 feet of an industrial ore heap leach bed. Compaction which occurs due to the weight of the ore in the heap may be partially responsible for the fine particle buildup which is found within the leaching heaps. Compaction causes a breakdown of the agglomerates which leads to a decrease in void space in the ore bed. The migration of fines in these compacted areas leave dead zones in which solution cannot flow, leaving them partially, or un-leached. To determine the effect of binders under compaction a special apparatus, adapted from the flooded column set-up, has been designed and constructed. The investigators of this project at Michigan Technological University are currently in the process of fully patenting this apparatus. MTU currently holds a provisional patent, serial number US60/750,236, on this apparatus. Work is being done to introduce the idea of compaction and its importance to help gather industrial interest in the area of compaction.

A scale up model of the long-term leach column which incorporates compaction has also been developed. This apparatus is also covered under the provisional patent serial number US60/750,236, held by the MTU investigators. The scale up will allow for the effect of the binders on copper recovery to be tested under simulated compaction conditions which may be found at various locations within the heap, but in the laboratory without using an excess amount of ore. In the future, multiple long-term leach compaction columns could be connected together to simulate all the compaction levels of an entire heap without having to run a test heap. Lateral effects in the heap will be one of the only things which will not be able to be simulated due to the limitation of laboratory column width.

The use of a proper binder will result in a more uniform percolation throughout the heap, which will help to decrease the amount of energy used by shortening the number of days 
the ore needs to be leached. The results from the soak tests show that non-ionic and slightly cationic polymer binders produce the greatest agglomerate strength under acidic conditions. The results from the flooded column tests indicate that the use of a binder for heap leaching agglomeration will help to increase the ability for solution to flow through the ore bed. This increase in solution flow will result in better contact between the solution and the ore and allow for the chemical reactions taking place to produce increased copper recovery rates.

\section{Industrial Involvement}

Michigan Technological University’s (MTU) industrial sponsors, Phelps Dodge Corp., have provided considerable amounts of engineering time to this project. They have provided experimental apparatus for conducting flooded and column leaching tests. Phelps Dodge has also provided several hundred pounds of their Mine for Leach (MFL) ore for experimental testing along with several hundred gallons of the raffinate solution from their process. Phelps Dodge has completed analysis on the material which they have sent, such as running assays and x-ray diffraction. They have also provided the use of their labs and employees to run duplicate 180 day leach column testing at their facility along with the testing which was being completed at MTU.

In July of 2005, a roundtable meeting between Michigan Technological University and the Phelps Dodge Industrial Team was held to discuss many issues revolving around the results, collected from the soak tests and flooded column tests, performed by Michigan Tech. The Phelps Dodge Industrial Team was comprised of the hydrometallurgical manager at their Bagdad facility, and the research engineer and lead research technician whom were assigned to the internal Phelps Dodge project. Issues were discussed such as the test work being run at Michigan Tech and the Process Technology Center, along with the complexities which our industrial partners would like to see addressed in order to implement MTU's ideas on an industrial scale.

In March of 2006, a conference call was organized between Phelps Dodge and the researchers at Michigan Technological University. This meeting allowed the MTU team to update the Phelps Dodge group of recent results from the compaction studies. Questions were addressed in relation to the results presented by MTU. Issues were also discussed such as the direction in which both MTU and Phelps Dodge would like to see the project progress. A follow up meeting at the 2006 Society for Mining, Metallurgy, and Exploration (SME) conference was conducted.

Every month a report was written by Michigan Tech to update Phelps Dodge on the status of the project. This report was distributed throughout all of the Phelps Dodge locations. Bi-weekly communication was also often made between the Phelps Dodge employees and the Michigan Tech researchers. Although there was close communication between the University and industry, the roundtable meeting and conference call gave the opportunity to communicate in person with the Phelps Dodge team. The involvement of 
our industrial partners will help in the implementation of any agglomeration technologies developed by this project.

\section{Educational Opportunity}

This project has allowed for various educational opportunities in relation to the project itself. Several undergraduate students have been given an opportunity to assist in research and testing. Analysis from soak tests, flooded column tests, and long term leach columns was contributed to by several undergraduate chemical engineering students at Michigan Technological University. This experience gave the students a chance to partake in many aspects of the research rather than just performing manual labor tasks. Students took part in designing or constructing laboratory apparatus', along with carrying out experimental procedures, and collecting and analyzing results. One particular undergraduate student is part author on this report along with being one of three inventors that took part in the design, creation, and patenting process of a large compaction column defined under provisional patent serial number US60/750,236.

This project has also lead to the completion of a paper (Eisele, et al., 2005) which was presented at the Society for Mining, Metallurgy, and Exploration (SME) Conference in Salt Lake City, Utah in 2005. This paper covers the determination of the acid resistance of agglomerates in copper heap leaching. An invited paper (Lewandowski, et al., 2006) was presented at the Sohn International Symposium on Advanced Processing of Metals and Materials: Principles, Technologies and Industrial Practice in San Diego, California in August 2006.

\section{Introduction}

The high grade ores which were once easily mined have become depleted. The metal in the lower grade ores is able to be recovered by heap leaching. Heap leaching is a method that is used to recover metal from lower grade ores in a reasonable amount of time, at low capital, and with low operating costs (Eisele et al., 1984; Dixon, 2003; McClelland, 1985; Weir, 1984).

The basic approach to hydrometallurgical processing of a secondary sulfide such as chalcocite $\left(\mathrm{Cu}_{2} \mathrm{~S}\right)$ is a chemical dissolution process (Bartlett, 1997; Ferron, 2003; Hiskey, 1986; Petersen, 2003; Uhrie, 2003). The liberation of copper from the mineral is done through a two-step chemical reaction with iron $\left(\mathrm{Fe}^{3+}\right)$, as illustrated in Equations 1 and 2 below.

$$
\begin{aligned}
\mathrm{Cu}_{2} \mathrm{~S}+2 \mathrm{Fe}^{3+} & \rightarrow \mathrm{Cu}^{2+}+2 \mathrm{Fe}^{2+}+\mathrm{CuS} \\
\mathrm{CuS}+2 \mathrm{Fe}^{3+} & \rightarrow \mathrm{Cu}^{2+}+2 \mathrm{Fe}^{2+}+\mathrm{S}^{0}
\end{aligned}
$$

The iron $\left(\mathrm{Fe}^{3+}\right)$ is then regenerated from iron $\left(\mathrm{Fe}^{2+}\right)$ using the bacterial reaction shown in Equation 3, which consumes oxygen and acid: 


$$
2 \mathrm{Fe}^{2+}+1 / 2 \mathrm{O}_{2}+2 \mathrm{H}^{+} \rightarrow 2 \mathrm{Fe}^{3+}+\mathrm{H}_{2} \mathrm{O}
$$

From these reactions, it can be seen that heap leaching of copper sulfide minerals requires the ability for solution, with dissolved iron, to maintain access to the ore particles. The iron $\left(\mathrm{Fe}^{3+}\right)$ reacts with the ore $\left(\mathrm{Cu}_{2} \mathrm{~S}\right)$, to produce the desired product, copper. It also requires easy flow of air to provide oxygen. The oxygen reacts with the iron $\left(\mathrm{Fe}^{2+}\right)$ produced from the ore reaction and with the aid of the bacteria reconverts back into iron $\left(\mathrm{Fe}^{3+}\right)$, which is a feed material for the other reactions. It is important that all of the equations continue, to obtain the best copper recovery possible.

In a copper heap leaching process, shown in Figure 1 (GE Infrastructure, 2004), the ore is crushed to an appropriate size, typically a top size of 0.5 inches. It is then transported to a pad and placed on top of an aeration system to a set height, known as a lift. Lift heights vary from mine to mine, but approximately 20 feet is typical. The lift is irrigated with the leach solution, raffinate, either by drip emitters or a sprinkler system. The raffinate then percolates through the heap while air is being blown from the bottom allowing iron $\left(\mathrm{Fe}^{3+}\right)$ to be regenerated by the bacterial reaction shown in Equation 3. The interaction between the raffinate, air, and ore allow for the copper to be dissolved from the ore as indicated in Equations 1 and 2. The solution which has percolated through the heap, now referred to as pregnant leach solution (PLS), is captured in a pond. From the pond it is sent to a solvent extraction and electrowinning circuit where the liberated copper is ultimately recovered.

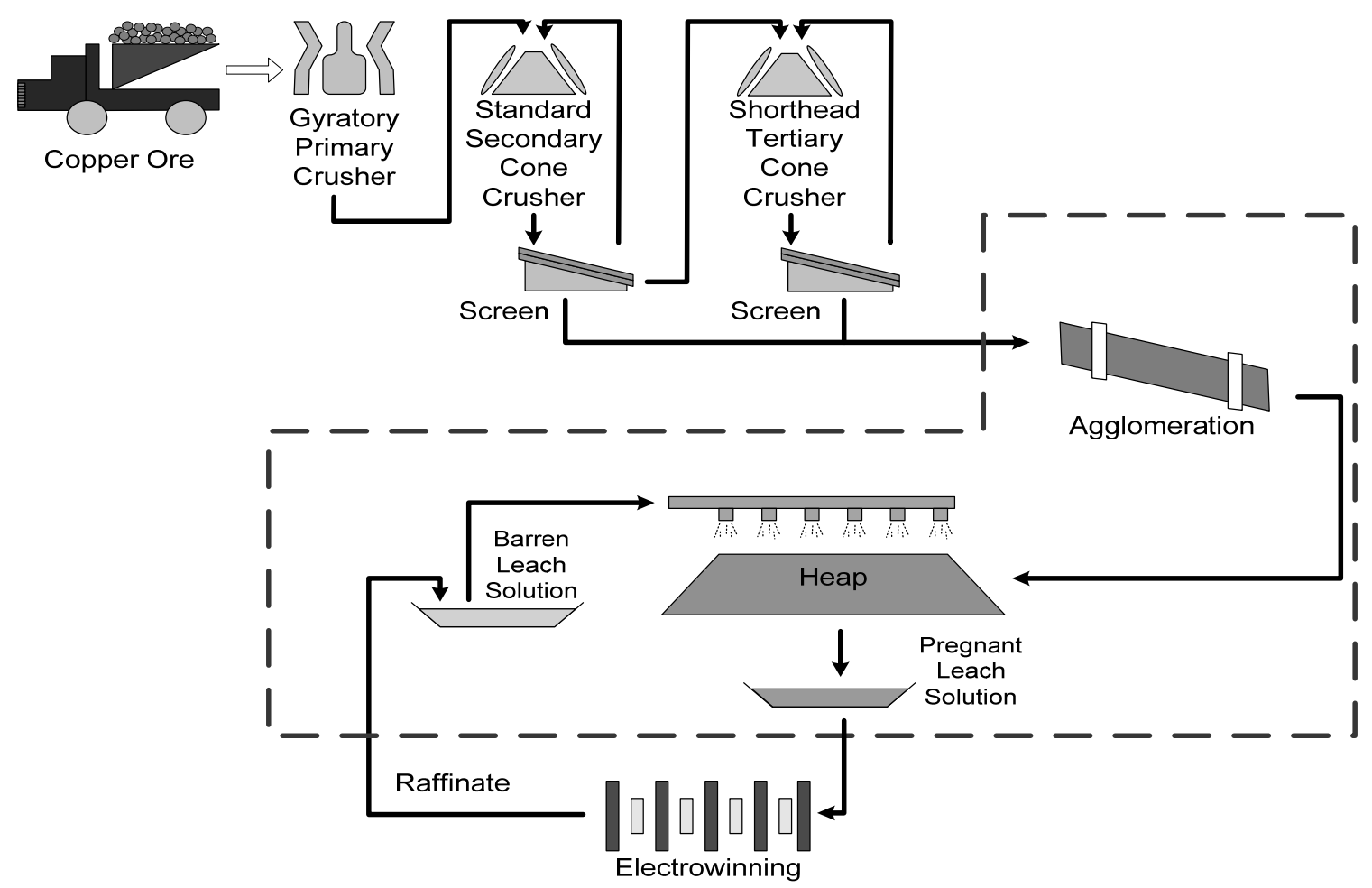

Figure 1: Copper Heap Leaching Process 
In the current heap leaching operations, the copper recovery rate and the ultimate copper recovery are still not as high as desired. This means it is necessary for ore to be ground to finer particle sizes in order for copper minerals to be exposed so that they can be leached more rapidly and completely. The finer-grained ore is much harder to handle, and is still not producing the required recoveries with the current operating conditions. Poor permeability is one of the main problems which results due to the finer-grained ore. The fine particles migrate downward in the heap with the leach solution, and clog the spaces between the larger ore particles causing uneven distribution of the leach solution, shown in Figure 2. The fine particles build up and begin to form impermeable layers within the ore bed. The build-up leads to a difficulty for air and leach solution to flow freely through the heap. Thus, the solution chooses to either flow down the path that gives the least amount of resistance (channeling), or tends to pool within the heap (ponding). Either of these actions will result in solution not coming in contact with all the ore, leaving these zones either non-leached, or partially leached only by diffusion. The air may also channel upwards creating the same problems associated with solution channeling. Ore which is not leached or partially leached in the heap means there is still available metal which is left un-recovered. To recover the metal, the heaps have to be run for an extended period of time, which leads to a loss in profit or an increase in the amount of energy needed to extract the un-leached metal.

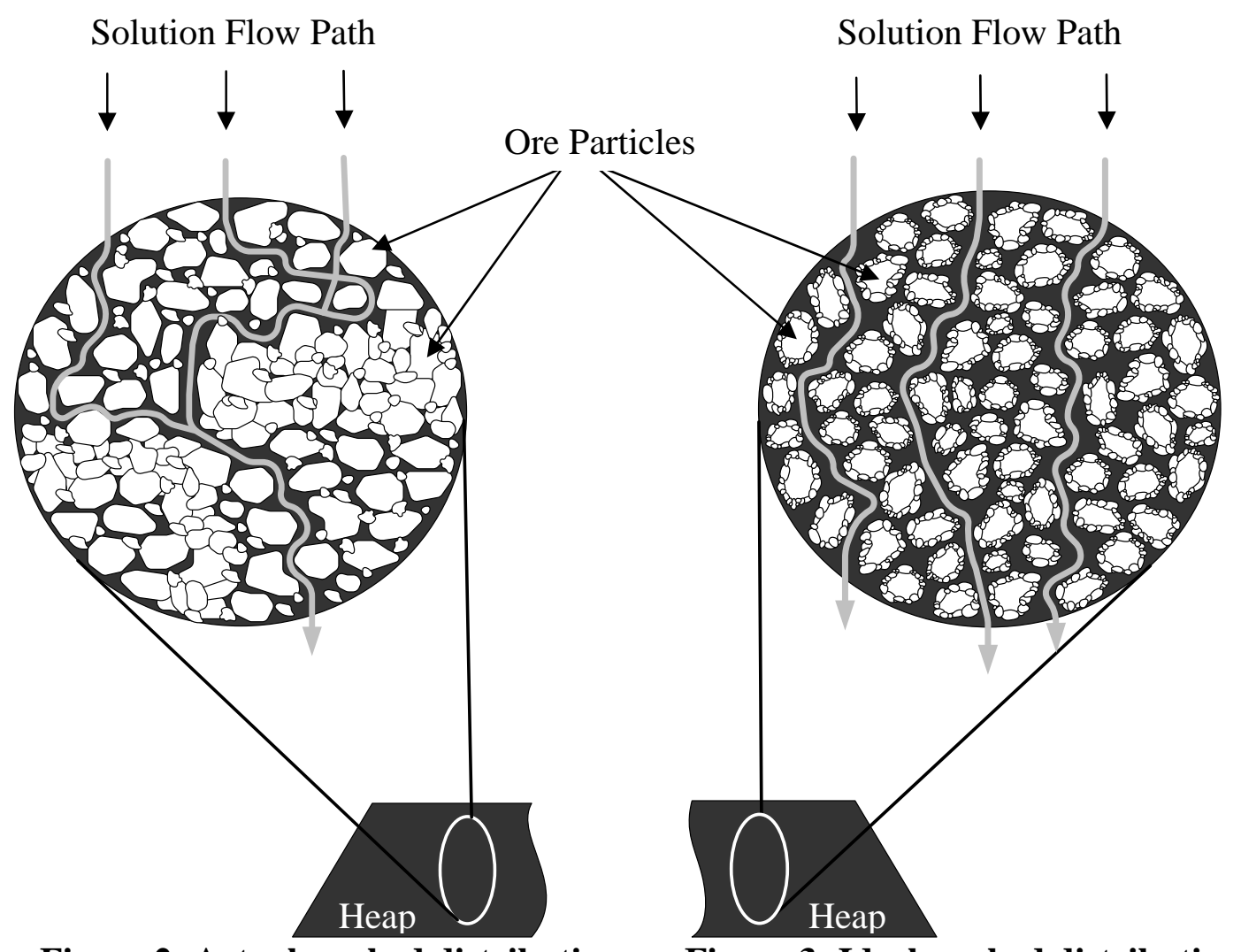

Figure 2: Actual ore bed distribution

Figure 3: Ideal ore bed distribution 
Ideally, the ore bed would be constructed of an ore distribution as illustrated in Figure 3. Spaces between the particles would create a more permeable ore bed which would allow for solution to flow freely and evenly through the heap, and would allow air to flow upwards. There would be limited free fine particles which would clog spaces and result in permeability problems. Agglomeration can be used to achieve this ideal ore bed distribution. Agglomerating the material into pellets, similar masses, or particles that are durable enough to be handled would entrap the fine particles, preventing them from filling the spaces between the larger particles and causing build-up. Agglomerating and entrapping the fine particles, allows for an increase in the availability of the transport of the leach solution throughout the heap. When the leach solution percolates evenly through the heap the reactions within the heap can take place within all the ore. Agglomeration has been shown to be important in the heap leaching of metals, such as gold and copper.

In copper heap leaching processes, after the ore is crushed it can be sent to an agglomeration drum, where it is agglomerated with raffinate (leach solution). The agglomerated ore is transported to the heap by conveyor, where it is radially stacked. Currently, there is one copper heap leaching facility in the United States which uses agglomeration as described above. This facility is still observing copper outputs below the desired recovery rate, due to the rapid breakdown of the agglomerates. This breakdown is caused by the release of fine material which clogs flow channels in the ore bed. Areas are left either un-leached or partially leached, and void of the necessary reagents to dissolve the copper. To get the desired copper recovery rates, there needs to be an even greater increase in permeability within the heap. An increase in permeability by agglomeration will allow for the leach solution to reach the ore in the entire heap evenly. To understand what could be done to produce agglomerates that would not break down, the mechanisms of binding in agglomeration were studied.

\section{Agglomeration Binding Mechanisms}

Pietsch (2002) had divided the binding mechanisms of agglomeration, first defined and classified by Rumpf (1975), into the following five categories; (I) Solid bridges, (II) adhesion and cohesion forces, (III) surface tension and capillary pressure, (IV) attraction forces between solids, and (V) interlocking bonds. Although these mechanisms have been classified into categories, it was unlikely that only one mechanism takes place in agglomerates. Rather, it was most likely a combination of several. Each binding mechanism will be discussed in further detail (Pietsch, 2002).

I. Solid bridges can be formed by sintering, partial melting, chemical reactions, hardening binders, re-crystallization and during drying. Sintering, partial melting, and re-crystallization often form solid bridges due to a change in temperature of the system, shown in Figure 45A (Pietsch, 2002). As the temperature rises, melting occurs. The bridges are formed as the material cools. Solid bridges formed by chemical reactions or hardening binders often take place with the 
addition of moisture, shown in Figure 4B and C (Pietsch, 2002). Elevated temperature and pressure may increase the strength of these bridges.

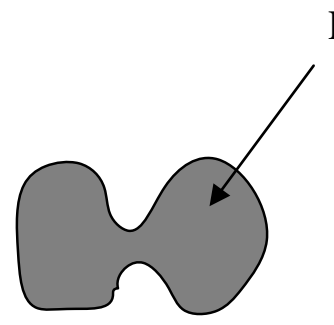

(A)

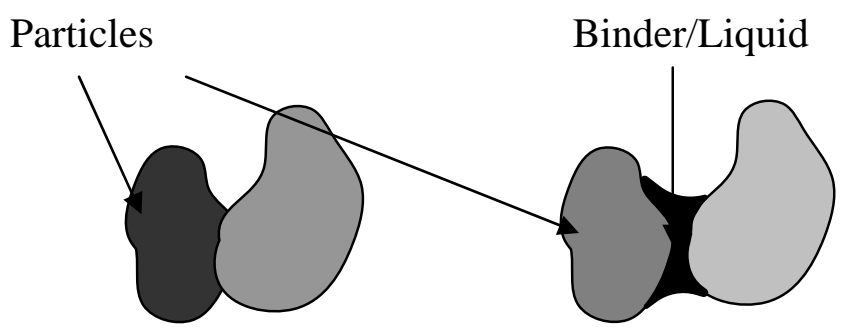

(B)

(C)

Figure 4: Examples of solid bridges that have formed between two particles. (A) Solid bridges due to sintering, partial melting, or crystallization. (B) Solid bridges formed due to chemical reactions or hardening binders. (C) Solid bridges formed from chemical reactions, hardening binders, or crystallization.

II. Adhesion and cohesion forces occur at solid-liquid interfaces when highly viscous binders, such as honey, pitch, tar, etc., are employed. These forces also lead to the attraction of free atoms or molecules from the surrounding atmosphere to the surface of the solids, forming adsorption layers (Pietsch, 2002). Examples of the adhesion and cohesion forces that occur at the solid-liquid interfaces are shown in Figure 5 (Pietsch, 2002).

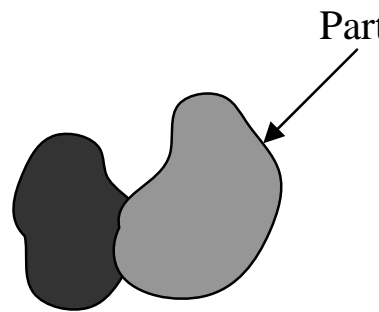

(A)

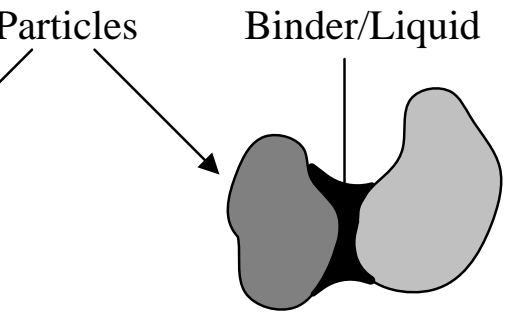

(B)

Figure 5: Examples of adhesion and cohesion forces that occur at solid-liquid interfaces. (A) Adhesion and cohesion forces due to viscous binders and adsorption layers. (B) Adhesion and cohesion forces due to viscous binders

III. Surface tension and capillary forces are key factors in wet agglomeration. The agglomerates were bonded by liquid bridges that form from free water or capillary condensation, shown in Figure 6 (Pietsch, 2002). Capillary pressure is created when the entire pore volume between particles fills with liquid causing menisci to form at the pore ends. This leads to a negative capillary pressure which gives the agglomerate added strength. Although, the surface tension bonding alone often does not provide strong enough forces to withstand handling conditions after the material has been agglomerated. 


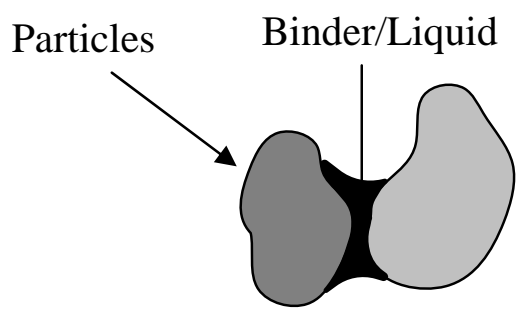

Figure 6: Example of liquid bridge which bonds agglomerations through surface tension and capillary forces.

IV. The attraction forces between solid particles were mainly (i) molecular, (ii) electric, and (iii) magnetic forces, depicted in Figure 7 (Pietsch, 2002). At small distances the effect of these forces can be great, although they decrease quickly with distance. These forces may also enhance the forces due to the other binding mechanisms.

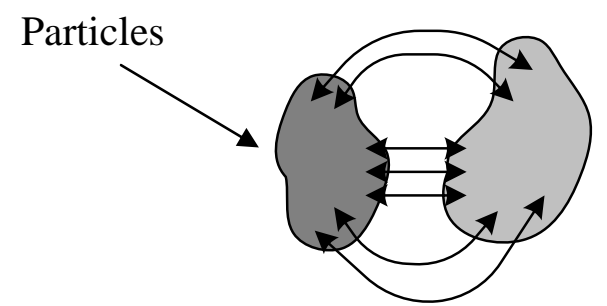

Figure 7: Example of attraction forces between particles. These forces may also enhance the forces due to the other binding mechanisms.

i. The molecular forces include (a) van der Waals forces, (b) valence forces, and (c) non-valence association.

a. Van der Waals forces are physical forces of attraction and repulsion existing between molecules which occur due to polarization induced in each particle by the presence of others.

b. Valence forces arise when the bonds between atoms or molecules are broken creating new surfaces with unsatisfied valences. If the newly created surface area was large, the valences themselves may recombine if newly created surfaces come close to each other.

c. Non-valence association includes hydrogen bonding. Hydrogen bonding occurs when hydrogen atoms are bonded by polar covalent bonds to a small atom of high electronegativity. The hydrogen atom interacts with the non-binding electron pair of another electronegative atom. 
ii. Electric forces may exist due to unsatisfied electrostatic fields. When two solids with unsatisfied electrostatic fields come in contact, electrical double layers are formed. The electric double layer was formed due to the migration of electrons between particles, until equilibrium was reached.

iii. Magnetic forces act similar to that of electrostatic forces. This mechanism was limited to particles which possess magnetic properties.

V. When particles entangle during agglomeration, interlocking bonds occur, shown in Figure 8 (Pietsch, 2002). This mechanism may also occur if the particles were compacted.

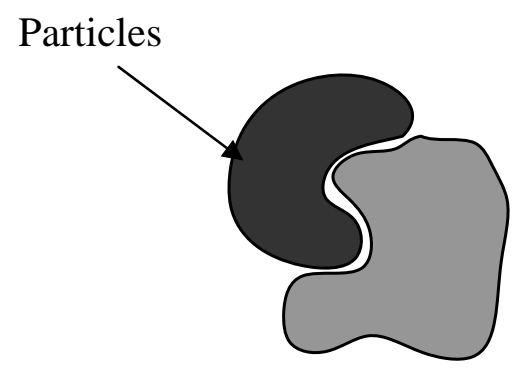

Figure 8: Example of interlocking bonds between particles.

When natural binding mechanisms, such as interlocking bonds, attractive forces, or bridging due to mechanical energy being converted to thermal energy, fail to produce stable agglomerates, an additional binding additive needs to be utilized. These binding agents would primarily utilize a combination of adhesion, cohesion, surface tension, capillary, and attractive forces. It was unlikely that only one mechanism was taking place binding agglomerates. The strength of the agglomerate, and the binding mechanism employed, was based on several things such as the type of material which was being used, the binder which was being added, the amount of moisture addition, and the reactions that take place within the agglomerate. In heap leaching, solid bonds were formed by hardening, or highly viscous, binders, producing the most stable agglomerates, which help maintain the permeability of the heap.

The use of a cost effective binder in the agglomeration step could greatly enhance the overall recovery of the heap by preventing agglomerate breakdown and limiting the migration of fines. The result would be an increase in the permeability of the heap. However, copper leaching requires a high use of acid solutions to help the bacteria convert iron $\left(\mathrm{Fe}^{2+}\right)$ back into iron $\left(\mathrm{Fe}^{3+}\right)$. The acidic solutions decrease the $\mathrm{pH}$ of the heap to approximately a $\mathrm{pH}$ of 1.5-3. Most agglomeration binders which are used successfully in other operations, such as Portland cement and lime, require a more neutral or alkaline $\mathrm{pH}$. These cement-type binders dissolve readily in acid, and are completely ineffective in an acidic leaching environment. Acid-resistant binders are needed for these copper operations which will not breakdown in acid, while allowing access of air and leach solutions to reach the ore particles. 
The use of a proper binder will result in a more uniform percolation throughout the heap, which will help to decrease the amount of energy used by shortening the number of days the ore needs to be leached.

\section{Energy Saving Benefits}

Increasing copper recovery in heap leaching by the use of binders and agglomeration would result in a significant decrease in the amount of energy consumed. Assuming that $70 \%$ of all the leaching heaps would convert to using agglomeration technology, as much as $1.64 * 10^{12}$ BTU per year would be able to be saved if a $25 \%$ increase in copper recovery was experienced. This is the equivalent to saving approximately $18 \%$ of the energy currently being used in leaching heaps.

Our industrial partner, Phelps Dodge Corp., is the largest copper heap leaching operation in the United States. Therefore, predicted energy savings were based off of data received through personal communication with Phelps Dodge Corp. in May of 2002. These energy saving values are also applicable to other heap leaching operations, as long as it is noted that the increase in recovery due to agglomeration will vary considerable depending on the nature of the ore in any given situation.

In 2002, approximately 601,000 tons of copper were produced in the United States by heap leaching processes. This was $1 / 2$ of the total 1.14 million tons of copper produced that year. The Phelps Dodge Morenci operation alone was responsible for producing 410,000 tons of the copper produced in the United States at that time. It is assumed that each unit, or leach heap, produces 2000 tons of copper per year. There were 301 units in the United States in 2002. The Phelps Dodge Corp. is responsible for 205 of the 301 units.

In 2002, Phelps Dodge consumed a grand total of $3.04 * 10^{10} \mathrm{BTU} / \mathrm{unit} / \mathrm{yr}$ between diesel fuel and electricity, as shown in Table 1. Diesel fuel consumed the greatest amount of energy at $5.71 * 10^{9} \mathrm{BTU} / \mathrm{unit} / \mathrm{yr}$ and electricity at $2.47 * 10^{10} \mathrm{BTU} / \mathrm{unit} / \mathrm{yr}$.

Table 1: Energy Consumption at Phelps Dodge in 2002

\begin{tabular}{|c|c|}
\hline \multicolumn{2}{|c|}{$\begin{array}{c}\text { Current Technology } \\
\text { BTU/Yr/Unit }\end{array}$} \\
\hline Diesel Fuel & $2.47 \mathrm{E}+10$ \\
\hline Electricity & $5.71 \mathrm{E}+09$ \\
\hline Total & $3.04 \mathrm{E}+10$ \\
\hline
\end{tabular}

*One unit is equal to one leaching heap extracting 2000 tons of copper per year

It was estimated that at the Phelps Dodge Morenci operation, every 1\% improvement in copper recovery would result in savings of 1.1 million $\mathrm{kW}$-hr per year in electricity and 400,000 gallons/yr of diesel fuel. Energy savings with the use of binders and agglomeration in heap leaching were calculated using Equation 4 and 5. The energy savings for increasing percent of copper recovery are listed in Table 2 along side the 
energy consumption which would be associated with the implementation of the proposed agglomeration technology.

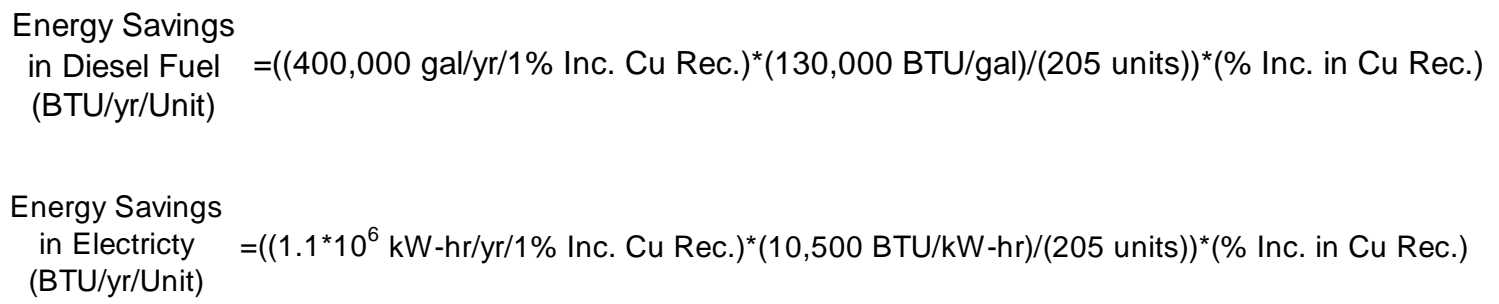

Cumulative energy savings are based off of the assumption that in 10 years an estimated $70 \%$ of the current 301 copper leaching units would be able to use or implement the agglomeration and binder technology. Total cumulative energy savings are calculated using Equation 6.

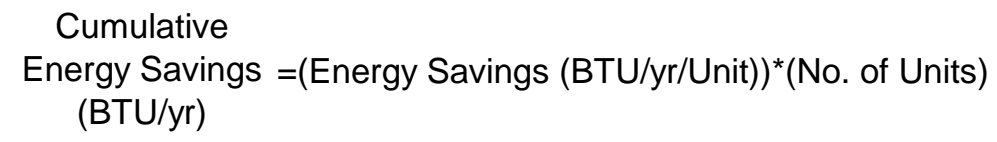

Table 2: Energy Savings with Percent Increase in Copper Recovery with Proposed Agglomeration Technology

\begin{tabular}{|c|c|c|c|c|c|c|}
\hline \multirow[t]{2}{*}{$\begin{array}{c}\text { Increase } \\
\text { in Cu } \\
\text { Recovery } \\
(\%)\end{array}$} & \multicolumn{2}{|c|}{$\begin{array}{c}\text { Proposed Technology } \\
\text { (BTU/Yr/Unit) }\end{array}$} & \multicolumn{2}{|c|}{$\begin{array}{c}\text { Energy Savings } \\
\text { (BTU/yr/Unit) }\end{array}$} & $\begin{array}{l}\text { No. of } \\
\text { Units }\end{array}$ & $\begin{array}{c}\text { Cumulative Energy Savings } \\
\text { (BTU/Yr) }\end{array}$ \\
\hline & Diesel Fuel Electricity & Total & Diesel Fuel Electricity & Total & & \begin{tabular}{l|l} 
Diesel Fuel Electricity \\
\end{tabular} \\
\hline
\end{tabular}

\begin{tabular}{|c|c|c|c|c|c|c|c|c|c|c|}
\hline 1 & $2.44 \mathrm{E}+10$ & $5.66 \mathrm{E}+09$ & $3.01 \mathrm{E}+10$ & $2.54 \mathrm{E}+08$ & $5.63 \mathrm{E}+07$ & $3.10 \mathrm{E}+08$ & 211 & $5.35 \mathrm{E}+10$ & $1.19 \mathrm{E}+10$ & $6.54 \mathrm{E}+10$ \\
\hline 2 & $2.42 \mathrm{E}+10$ & $5.60 \mathrm{E}+09$ & $2.98 \mathrm{E}+10$ & $5.07 \mathrm{E}+08$ & $1.13 \mathrm{E}+08$ & $6.20 \mathrm{E}+08$ & 211 & $1.07 \mathrm{E}+11$ & $2.38 \mathrm{E}+10$ & $1.31 \mathrm{E}+11$ \\
\hline 3 & $2.39 \mathrm{E}+10$ & $5.54 \mathrm{E}+09$ & $2.95 \mathrm{E}+10$ & $7.61 \mathrm{E}+08$ & $1.69 \mathrm{E}+08$ & $9.30 \mathrm{E}+08$ & 211 & $1.61 \mathrm{E}+11$ & $3.57 \mathrm{E}+10$ & $1.96 \mathrm{E}+11$ \\
\hline 4 & $2.37 \mathrm{E}+10$ & $5.49 \mathrm{E}+09$ & $2.91 \mathrm{E}+10$ & $1.01 \mathrm{E}+09$ & $2.25 \mathrm{E}+08$ & $1.24 \mathrm{E}+09$ & 211 & $2.14 \mathrm{E}+11$ & $4.76 \mathrm{E}+10$ & $2.62 \mathrm{E}+11$ \\
\hline 5 & $2.34 \mathrm{E}+10$ & $5.43 \mathrm{E}+09$ & $2.88 \mathrm{E}+10$ & $1.27 \mathrm{E}+09$ & $2.82 \mathrm{E}+08$ & $1.55 \mathrm{E}+09$ & 211 & $2.68 \mathrm{E}+11$ & $5.94 \mathrm{E}+10$ & $3.27 \mathrm{E}+11$ \\
\hline 10 & $2.21 \mathrm{E}+10$ & $5.15 \mathrm{E}+09$ & $2.73 \mathrm{E}+10$ & $2.54 \mathrm{E}+09$ & $5.63 \mathrm{E}+08$ & $3.10 \mathrm{E}+09$ & 211 & $5.35 \mathrm{E}+11$ & $1.19 \mathrm{E}+11$ & $6.54 \mathrm{E}+11$ \\
\hline 15 & $2.09 \mathrm{E}+10$ & $4.87 \mathrm{E}+09$ & $2.57 \mathrm{E}+10$ & $3.80 \mathrm{E}+09$ & $8.45 \mathrm{E}+08$ & $4.65 \mathrm{E}+09$ & 211 & $8.03 \mathrm{E}+11$ & $1.78 \mathrm{E}+11$ & $9.81 \mathrm{E}+11$ \\
\hline 20 & $1.96 \mathrm{E}+10$ & $4.59 \mathrm{E}+09$ & $2.42 \mathrm{E}+10$ & $5.07 \mathrm{E}+09$ & $1.13 \mathrm{E}+09$ & $6.20 \mathrm{E}+09$ & 211 & $1.07 \mathrm{E}+12$ & $2.38 \mathrm{E}+11$ & $1.31 \mathrm{E}+12$ \\
\hline 25 & $1.83 \mathrm{E}+10$ & $4.30 \mathrm{E}+09$ & $2.26 \mathrm{E}+10$ & $6.34 \mathrm{E}+09$ & $1.41 \mathrm{E}+09$ & $7.75 \mathrm{E}+09$ & 211 & $1.34 \mathrm{E}+12$ & $2.97 \mathrm{E}+11$ & $1.64 \mathrm{E}+12$ \\
\hline
\end{tabular}

$*$ One unit is equal to one leaching heap extracting 2000 tons of copper per year

Increasing the percent of copper recovery from a heap, results in a decrease in the amount of energy consumed by heap leaching processes, Figure 9 and Table 2 . The current technology has not allowed for an increase in copper recovery. Therefore, the energy consumption of the current heap leaching process is shown in Figure 9 by a horizontal line for all increases in copper recovery, for comparison purposes. Energy savings from a decrease in the amount of diesel fuel makes up the greatest fraction of the total amount of energy which will be saved with the use of agglomeration. 


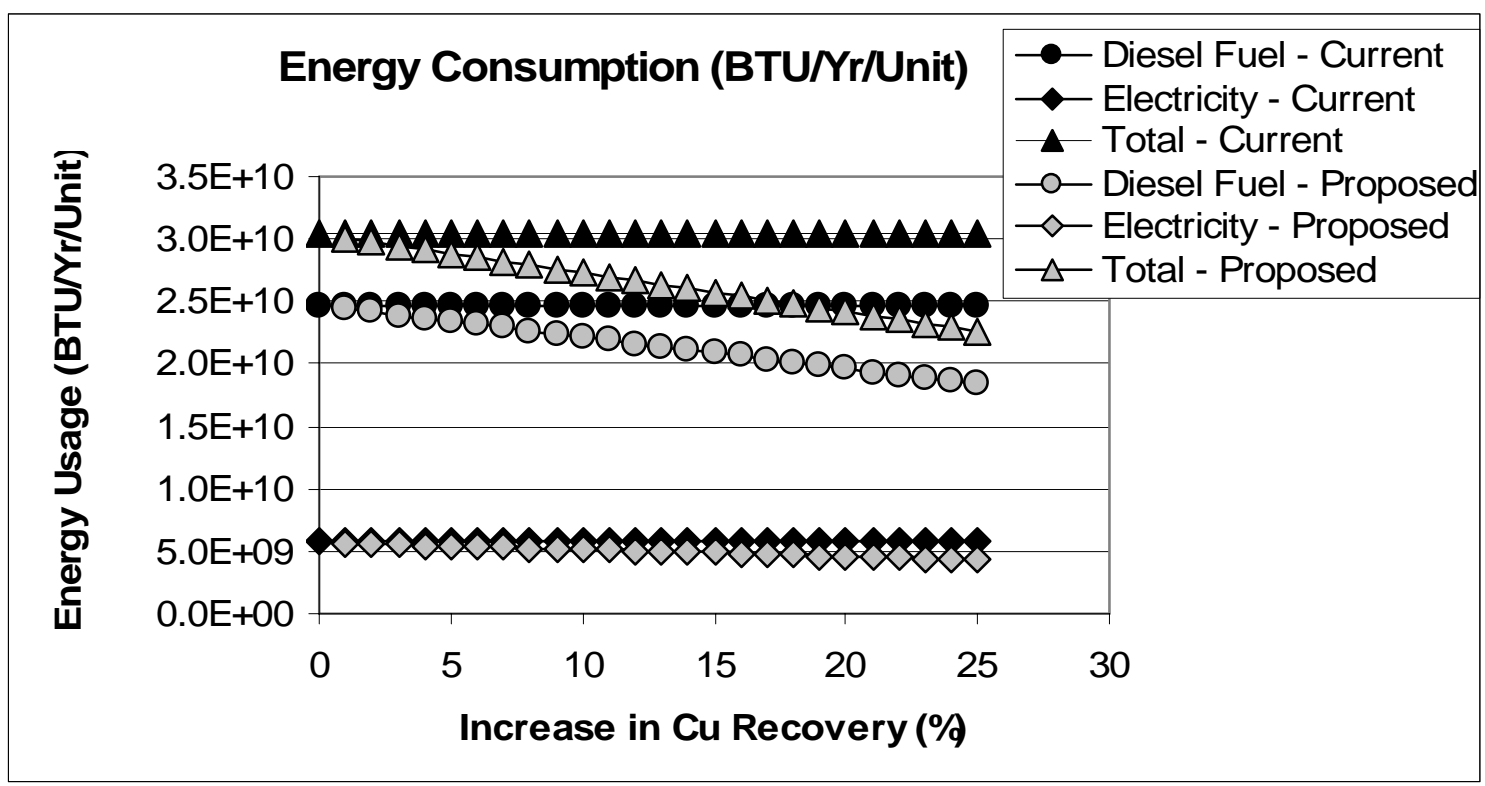

*One unit is equal to one leaching heap extracting 2000 tons of copper per year

Figure 9: Energy consumption comparison between the current energy consumption at a copper heap leaching facility and the energy consumption associated with the increase in copper recovery due to the proposed agglomeration technology changes.

Cumulative energy savings, Figure 10 and Table 2, take into account the total amount of energy which will be saved assuming that $70 \%$ of the 301 heap leaching units convert to using the agglomeration technology. As much as $1.64 * 10^{12}$ BTU per year will be able to be saved if a $25 \%$ increase in copper recovery was experienced. This is the equivalent to saving the energy of approximately 54 copper heap leaching units per year, or approximately $18 \%$ of the energy currently being used in leaching heaps.

Even if the copper recovery may not be able to be increased, the desired recovery may be achieved but with a shortened leach period. Shortening the leach cycle of a heap leach unit by one week allows for energy savings of $5.84 * 10^{8}$ BTU/Week/Unit or a total of $1.23 * 10^{11}$ BTU/Week assuming $70 \%$ of the total 301 units implement the technology. Achieving increased copper recovery along with a decrease in leach time will only amplify the energy saving results expected from either one of these alone. 


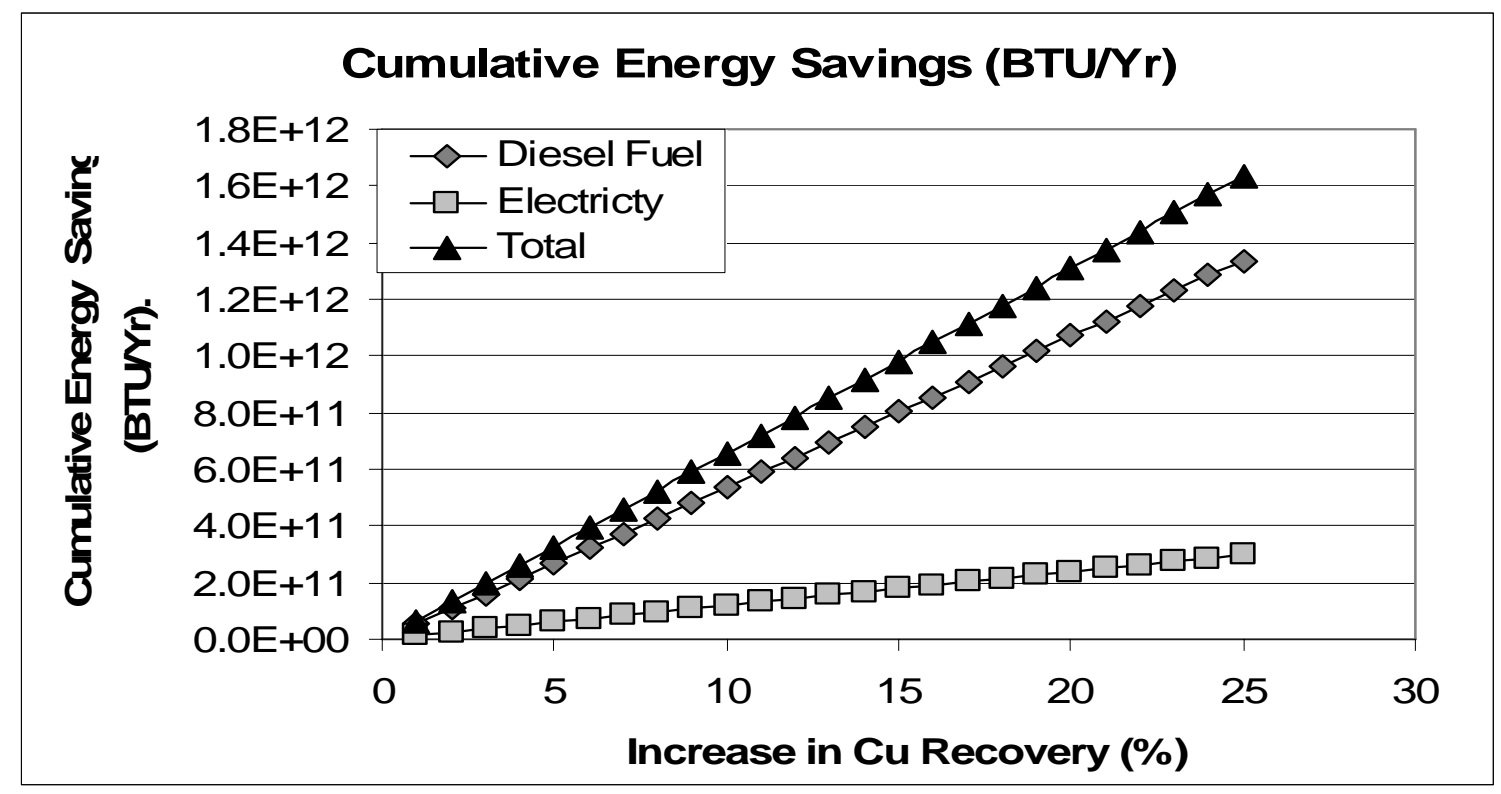

*One unit is equal to one leaching heap extracting 2000 tons of copper per year Figure 10: Cumulative energy savings per year with an increasing percent of copper recovery due to the implementation of the new agglomeration technology.

\section{Binders in Heap Leaching}

Once leaching begins, the agglomerates become wet, and they begin to break down and allow fines to migrate. An appropriate binder would adhere to the particles, holding the agglomerates together (Polizzotti et al., 1999). Binders are products which were added to increase the strength of agglomerates. The use of a binder would prevent the migration of fines, allowing air and leaching solution to percolate through the heap freely, resulting in improved leaching rates and metal recovery (McClelland, 1986).

Although von Michaelis (1992) stated there was no standard amount of fine material or clays that indicate a need for agglomeration or binders in heap leaching, a binding agent may be needed if $10 \%$ of the material was -75um (-200mesh) (Chamberlin, 1986). The binder was to be chosen based on the material being used and the product qualities desired (Pietsch, 2002).

Chamberlin (1986) stated that segregation of particle sizes within a heap creates areas with lower permeability due to a build up of fines in the spaces between the larger ore particles. A binder or additive would help the fine particles to adhere to the coarser particles, minimizing percolation and permeability problems. Increasing permeability would lead to an increase in metal recovery by increasing the contact available between the ore and leaching solution. More adequate aeration, a necessity in heap leaching, can also be obtained with the use of flocculants, or binders, when used to help improve porosity by flocculating fine particles (Aplan, 1995). A binder needs to be low in cost 
and needs to be able to increase recovery rates without increasing energy consumption (U.S. Department of Energy, 2004).

The majority of binders which were used in heap leaching were used or tested in noncopper or non acidic operations, such as the gold and silver industry. The use of binders was very limited in the copper industry, due to high acid concentrations needed for leaching (Efthymiou et al., 1998). For a binder to be considered useful in a copper leaching heap, it should have the following properties:

- Acid resistance

o Traditional cement-type binders, such as Type II Portland cement used in gold heap leaching (Chamberlin, 1986), break down in acid solution, and would be completely unsuitable for acid heap leaching (Serrano, 2003). Binders for copper leaching need to either be unaffected by acidic conditions or react with acid to form inter-particle bonds.

- Economical

o The chosen binder must not only be effective at low dosages, but must be inexpensive enough to use on a large scale.

- Non-hazardous and non-toxic to bacteria

o The binder chosen for the copper leach heaps needs to be non-toxic to the bacteria in the heap along with being non-hazardous and environmentally friendly. Bacterial activity is critical in the heap (Brierley and Brierley, 1999; Weir, 1984). The bacterial populations work as a catalyst to help oxidize the ferrous iron back to ferric iron. The ferric iron was needed for the further oxidation of the copper sulfide minerals. In addition to not interfering with the bacterial growth, the chosen product must also not be a handling concern for plant personnel.

A variety of binding agents have been tested in the gold, silver, nickel, and copper industries as agglomeration aides in prior studies, given in Table 3. The majority of the binders listed in Table 3 have been tested on gold/silver ore agglomerates, and include solution, dolomite, calcium chloride, magnesia, cement, lime, Leach-it, pulp, acrylamide/acrylic acid copolymers, polyvinyl alcohol, EO9760, and polyethylene oxide. However, as these binders were tested in a basic environment, they would not be suitable for the acidic conditions experienced in a copper heap leach. Eleven binders were tested on nickel ore, which also uses sulfuric acid for leaching similar to copper heap leaching, and only five of the binders listed in Table 1 have been tested in copper heap leaching agglomeration. The binders tested on nickel ore include agar, gelatin, gums, sodium carboxymethylcellulose, starch, clays, iron (II) sulfate, silicic acid, sodium tripolyphosphate, calcium sulfate, and silicates. Those tested on copper ore include, solution, acrylamide/acrylic acid copolymers, EO9560, polyacrylamide, and a proprietary polymer labeled Additive 3. A review of the studies completed on binders which were tested under acidic condition is given below. 
Table 3: Summary of Binders Tested in Various Leaching Operations

\begin{tabular}{|c|c|}
\hline Process Materials & Agglomerant \\
\hline No Added Binder & Leaching Solution \\
\hline \multirow{5}{*}{ Organic Binders } & Agar \\
\hline & Gelatin \\
\hline & Gums \\
\hline & Sodium Carboxymethylcellulose \\
\hline & Starch \\
\hline \multirow{11}{*}{ Inorganic Binders } & Calcined Dolomite, Calcium Chloride, Magnesia \\
\hline & Cement \\
\hline & Clays \\
\hline & Lime \\
\hline & Leach-it \\
\hline & Iron (II) Sulfate \\
\hline & Silicic Acid \\
\hline & Sodium Tripolyphosphate \\
\hline & Calcium Sulfate \\
\hline & Pulp \\
\hline & Silicates \\
\hline \multirow{7}{*}{ Polymer Binders } & Acrylamide/Acrylic Acid Copolymers \\
\hline & Cross-Linked Borated Polyvinyl Alcohols \\
\hline & Extract-Ore 9560 \\
\hline & Extract-Ore 9760 \\
\hline & Polyacrylamide \\
\hline & Polyethylene Oxide Resins \\
\hline & Other - Additive 1 \\
\hline
\end{tabular}

\section{Leaching Solution}

Leaching solution (raffinate) was used as a binder in several applications, or was often applied in addition to another binder, and can be a key parameter required to ensure 
the target recovery was achieved (Readett et al., 2003). This allowed for several different binding mechanisms due to the solution and the binder, to be employed. Surface tension forces and capillary action between the solution and the particles was sometimes enough for the fine material to hold to the coarser particles (von Michaelis, 1992; Fernández, 2003). The common agglomeration practice within the copper industry was to agglomerate using acid and raffinate (Uhrie, et al., 2003). Bridging structures may be formed by gypsum formation, binding copper ore particles together in acid agglomeration (Efthymiou, et al., 1998). Agglomeration solutions may also include water or leach solution, such as cyanide in gold and silver leaching heaps.

One method proposed by Chamberlin (1986) to agglomerate with solution, would be to run a truckload of ore under a solution spray to the desired moisture content. The ore was then mixed when it cascaded down the slope of the heap, or while it was being moved with a bulldozer. It may also be sprayed onto the ore at locations along a belt conveyor (McClelland, et al., 1983) or in an agglomeration drum.

The amount of moisture added in agglomeration is important (Butwell, 1990). McClelland et al. (1988) stated that "the proper moisture content for agglomeration was determined by the particle size, clay content, wetting characteristics, and desired degree of compaction during agglomeration”. McClelland and Eisele (1982) investigated the effect of moisture on percolation flow rates in a cement-water agglomerated gold-silver ore percolation column test. Solution flow rate increased with increasing water addition up to 12 wt-percent moisture and then decreased rapidly. Although, 12 wt-percent moisture was the optimum, moisture contents between 8 and 16 wt-percent were acceptable. The results indicated the permeability and percolation rates were dependent on the quantity of water used in agglomeration. If too much moisture was added, the capillary pressure in the agglomerate goes to zero due to the concave menisci on the agglomerates surface no longer being able to form, (Pietsch, 2002) and retain the surface tension and capillary forces. If this occurs, the material becomes mud like, would not agglomerate, and would not allow for percolation.

Fernández (2003) also determined that moisture content was important to the characteristics and long-term strength of the agglomerates. He stated that by not achieving the proposed dosage of the agglomerating liquid, this would result in size segregation during stacking and poor quality of agglomerates. These factors then lead to ponding, partial or non existent percolation, uneven permeability, limited irrigation flow rates, limited lift height, and ultimately deteriorated permeability. Fernández's (2003) agglomerated copper ore with varying amounts of moisture. The size distribution of the agglomerated ore was determined before the ore was stacked in a heap. Various zones, low, intermediate, and upper, within the heap were analyzed after leaching to determine the final size distribution. Results from Fernández's (2003) studies showed that the amount of cumulative material which was able to be retained in the agglomerates changed when the amount of moisture used in the agglomeration process was increased upwards towards the optimum moisture content. This indicated that if there was not enough solution used in agglomeration, the agglomerates would not be stable, and would 
eventually still release small particles which would migrate downwards through the heap, decreasing the heap permeability.

Agglomerating with solution alone, usually a mixture of acid and raffinate, in the copper industry has shown to increase the copper recovery by increasing the permeability of the heap, and therefore allowing for better aeration of the material (Lastra et al., 1984). However, the increase in copper recovery may also be due to the fact that the additional acid accelerates the ferrous oxidation in the first stage of chalcocite leaching (Uhrie, et al., 2003).

When using solution alone as an agglomerating aide, the agglomerates still tend to breakdown, thus, leaving room for improvement in agglomerate quality, which would help to increase recovery further.

\section{Organic Binders}

Acidithiobacillus ferrooxidans were one of the types of bacteria found in heap leaching. These bacteria obtain their carbon from atmospheric carbon dioxide. Southwood (1985), reports that these organisms cannot tolerate even small doses of certain organic compounds. Therefore, caution must be taken in selecting organic binding agents for agglomeration in heap leaching.

$\underline{\text { Agar }}$

Southwood (1985) stated that agar is a polysaccharide formed from plant matter such as seaweed. It was found that the use of agar in agglomeration of low-grade nickeliferous ore resulted in the agglomerates disintegrating on contact with dilute sulfuric acid. Southwood (1985) reported that the polysaccharide molecules of the agar hydrolyze in acid to form saccharide monomers. These saccharide monomers appear to reduce the adhesive properties of the agar.

\section{$\underline{\text { Gelatin }}$}

Southwood (1985) found that the use of gelatin in agglomeration of low-grade nickeliferous ore produced agglomerates which exhibited high strength and maintained their form when subjected to sulfuric acid. However, they became very soft afterwards. Due to this result, Southwood (1985) concluded that the cohesive properties of gelatin may decline severely in sulfuric acid. This breakdown of gelatin in acid may also further hinder the process due to the fact that gelatin contains a number of amino acids, two of which were derivatives of powerful bactericides.

\section{$\underline{\text { Gums }}$}

The gums examined by Southwood (1985) included guar, gums, gum arabic, tracanth gum, and xanthan gum. All the gums tested with low-grade nickeliferous ore failed to provide agglomerates which did not breakdown when subjected to sulfuric acid. 
Southwood (1985) stated that like most naturally derived polysaccharides of large molecular mass, the gums hydrolyze at low $\mathrm{pH}$ values.

\section{Sodium Carboxymethylcellulose}

Carboxymethylcellulose is stable within the $\mathrm{pH}$ range of 2 to 10, but was said to precipitate below a pH value of 2 (Southwood, 1985). Results presented in Southwood (1985) on low-grade nickeliferous ore indicated that agglomerates with low proportions of carboxymethylcellulose have negligible resistance to acid attack.

\section{$\underline{\text { Starch }}$}

Southwood (1985) reported that starch is a crystalline compound which was resistance to most natural enzymes. However, it was subjected to hydrolysis when it comes into contact with sulfuric acid, lowering the competence of the agglomerates.

\section{Inorganic Binders}

\section{Clays}

Southwood (1985), used bentonite, china clay, and Western Province ball clay in agglomeration tests on low-grade nickeliferous ore. A substantial volume increase in the agglomerates was noted. Southwood (1985) concluded this was due to water displacing cations from between the sheet in the silicate structure of the clay. When the agglomerates came in contact with acid or water they tended to breakdown, rapidly forming fine suspensions in the liquids.

\section{Iron (II) Sulfate}

It was recommended that sulfide ore concentrates should be agglomerated with 0.5 to 1.0 percent iron (II) sulfate to improve the agglomerates. It was found by Southwood (1985), that the adequacy of the sulfate agglomerates tended to decline rapidly when coming in contract with sulfuric acid. This was determined to be due to the fact that the ferrous sulfate lattice of the agglomerates was soluble enough to cause instantaneous disintegration of the pellet.

\section{$\underline{\text { Silicic Acid }}$}

Southwood (1985) believed that agglomerates prepared with low-grade nickeliferous ore and silicic acid would be bound by amorphous silicic acid, a compound which was said to be insoluble in acids and water. However, these agglomerates showed poor acid tolerance.

\section{$\underline{\text { Sodium Tripolyphosphate }}$}

Sodium tripolyphosphate was commonly used as a dispersant (Southwood, 1985). However, when using it as an agglomeration binder with low-grade nickeliferous ore, it 
was found to be soluble, and promoted disintegration of the agglomerates when coming in contact with sulfuric acid.

\section{$\underline{\text { Calcium Sulfate }}$}

Calcium sulfate was stated to have low solubility in sulfuric acid (Southwood, 1985). It was believed by Southwood (1985) that when calcium hydroxide and sulfuric acid was added together in agglomeration with low-grade nickeliferous ore, the reaction would produce calcium sulfate and water which would act as the binding agents. The agglomerates bound by calcium sulfate had poor acid tolerance. Southwood (1985) stated that the poor acid tolerance was most likely due to high carbonate content of the ore used (listed as being more than 3\% $\mathrm{CO}_{2}$ ). Agglomerates using calcium sulfate showed a good tolerance to sulfuric acid when using nickel ore from a different location, and 8, 12 , and $15 \%$ binder.

\section{$\underline{\text { Silicates }}$}

When coming in contact with sulfuric acid, sodium silicate decomposes into silicic acid (Southwood, 1985). It was earlier shown by Southwood (1985) that silicic acid does not perform well as a binder for agglomeration when it comes into contact with sulfuric acid. To improve the performance of silicates as a binder, several other chemical agents could be combined with the silicates. Suggested agents included lime, zinc oxide, sodium carbonate, fine silica powder, and sodium silicofluoride (Southwood, 1985).

\section{Polymer Binders}

\section{Acrylamide/Acrylic Acid Copolymers (AM/AA)}

Studies completed by Polizzotti, et al. (1999) indicated that not all acrylamide/acrylic acid (AM/AA) copolymers make desirable agglomerating agents for gold ore bodies. The degree of effectiveness of AM/AA copolymers as binders was dependent on AM/AA mole ratio, molecular weight, and application rate (Polizzotti, et al., 1999). The acrylamide/acrylic acid copolymers used in the experimentation completed by Polizzotti, et al. (1999) have been patented by Betz Laboratories, Inc. under patent numbers US 5,077,021, US 5,077,022, US 5,186,915, US 5,112,582 and US $5,211,920$. The best agents were found to be 70/30 to 90/10 AM/AA copolymers with molecular weights ranging from 1 to 10 million atomic mass units. Although, these agents did not help to increase gold recovery or the rate of recovery, when mixed with lime, they decreased the detoxification wash time, in comparison to cement.

E. Michael Kerr of Nalco Chemical Company developed a method where a combination of polymers would be used as agglomeration aids in copper and precious metal heap leaching (U.S. Patent 5,833,937). The method included agglomerating the material first with an anionic or non ionic water-soluble polymer followed by a second cationic water-soluble polymer. He suggested agglomerating with a 70/30 mole percent

polyacrylamide/sodium acrylate followed by a polydiallyldimethylammonium chloride, a 
90/10 mole percent polyacrylamide/diallyldimethylammonium chloride, or a 99/1 mole percent polydiallyldimethylammonium chloride/vinyltrimethoxysilane. This procedure was also documented using a polyacrylamide followed with a polydiallyldimethylammonium chloride, a 90/10 mole percent polyacrylamide/diallyldimethylammonium chloride, or a 99/1 mole percent polydiallyldimethylammonium chloride/vinyltrimethoxysilane. This combination could be tested if all reagents were available.

\section{$\underline{\text { Extract-Ore } 9560 \text { (EO9560 or Nalco 9560) }}$}

Extract-ore 9560 was a polymer developed by Nalco Australia. This moderately anionic, medium molecular weight, latex copolymer forms irreversible bonds between the polymer functional groups and the ore particles during agglomeration. The use of binders was very limited in the copper industry, due to high acid concentrations needed for leaching. The use of EO9560 was tested at the Nifty Copper Operation when it was determined that the capillary forces alone were not adequate to immobilize the fines within the heap (Efthymiou et al., 1998).

A production trial was carried out at the Nifty Copper Operation with the use of EO9560 in agglomeration of oxide copper ore at a dosage rate of $1,000 \mathrm{~g} /$ ton of ore. This trial resulted in several zones which were un-leached or partially leached. This was due to the migration of fines within the heap, primarily caused by compaction especially in the lower levels of the heap. Channeling also was observed in areas of coarser material. The trial heap was suspended due to decreased incremental metal extraction at the end of the trial. In spite of the negative factors such as channeling and migration of fines, the results from the production trial indicated copper recoveries significantly better than any other production method being employed at the time (Efthymiou et al., 1998).

Although the use of Nalco Extract-ore 9560 was considered a success at Nifty Copper Operation, several limitations were discovered. The performance of the binder was dependent on the proportion of shale ore in the agglomeration feed. The shale ore was fragile and tended to disintegrate under acidic conditions. Lift heights were also a concern. Hydraulic performance in the heap at extreme lift heights tended to decrease due to compaction, even with the use of EO9560 (Efthymiou et al., 1998).

\section{Polyacrylamide}

Polyacrylamide was one of the more common polymers used as a flocculant. It works by creating bridges between particles by polymer chains (Tramfloc, 2004). Tramfloc, Inc. (2004) states that polyacrylamides have some of the highest molecular weights, among synthesized industrial chemicals. This allows the intrinsic flocculating power to increase. Although testing results were not reported, Tramfloc, Inc. indicates that their flocculants were applicable in leaching areas such as uranium mining, copper mining, and other mineral processing applications. 
The Cuajone leaching facility in Peru reclaims run-of-mine ore from the oxide stockpiles. The ore was crushed, agglomerated, and then send to the leach heap. After crushing, the ore was belt agglomerated with a polyacrylamide-type binder and sulfuric acid (Gonzales et al., 1996). The operation at Cuajone was recently started, as of 1995, and the polyacrylamide-type binder was added from the beginning. Therefore, improvements in operating conditions were not discussed. Binder selection factors were also not discussed.

von Michaelis (1992) stated that polymeric flocculants, such as Percol 351 work well as agglomeration binders while keeping costs lower than using many specialty products.

E. Michael Kerr of Nalco Chemical Company developed a method where a combination of polymers would be used as agglomeration aids in copper and precious metal heap leaching (U.S. Patent 5,833,937). The method included agglomerating the material first with an anionic or non ionic water-soluble polymer followed by a second cationic water-soluble polymer. He suggested using a polyacrylamide in agglomeration followed by a polydiallyldimethylammonium chloride, a 90/10 mole percent polyacrylamide/diallyldimethylammonium chloride, or a 99/1 mole percent polydiallyldimethylammonium chloride/vinyltrimethoxysilane. This procedure was also documented using a 70/30 mole percent polyacrylamide/sodium acrylate combination followed with a polydiallyldimethylammonium chloride, a 90/10 mole percent polyacrylamide/diallyldimethylammonium chloride, or a 99/1 mole percent polydiallyldimethylammonium chloride/vinyltrimethoxysilane. This procedure could be tried if all reagents were available.

Anthony Gross of Nalco Chemical Company developed an anionic acrylamide polymer to be used as an agglomeration aid in copper heap leaching (U.S. Patent 4,875,935 and U.S. Patent 4,898,611). This acrylamide polymer contains at least 5 mole percent carboxylate or sulfonate groups and had a molecular weight of at least 100,000. To improve the performance with the use of this product, the molecular weight should be increased to at least 3,000,000. Other improvements stated include where the anionic acrylamide polymer was an acrylic acid, methacrylic acid polymer, or an acyrlamide-2acrylamido, 2-methylpropane sulfonic acid copolymer. The use of these binders allowed for increased flow rates in percolation column testing. Improved recoveries were determined from pilot scale leach columns with the use of these binders.

Other

The Research Centre for the Mining and Metallurgical Industry of Cuba (CIPIMM) has developed an agglomeration additive which was referred to as Additive 1 (Serrano, 2003). The operating conditions used to analyze Additive 1 on high grade, clay-bearing copper ore, in column tests, are listed in Table 4 (Serrano, 2003). 
Table 4: Operating Parameters used at CIPIMM using Additive 1 on High Grade, Clay-bearing Copper Ore

\begin{tabular}{|l|l|l|l|l|l|}
\hline Column & $\begin{array}{c}\text { Additive 1 } \\
\text { Dosage }(\mathrm{kg} / \mathrm{t})\end{array}$ & $\begin{array}{c}\text { Water } \\
(\mathrm{kg} / \mathrm{t})\end{array}$ & $\begin{array}{c}\text { Acid } \\
(\mathrm{kg} / \mathrm{t})\end{array}$ & $\begin{array}{c}\text { Curing } \\
\text { Time } \\
(\text { Days })\end{array}$ & $\begin{array}{c}\text { Initial Bed } \\
\text { Height } \\
(\mathrm{cm})\end{array}$ \\
\hline Column 1 & 0.0 & 157.8 & 20.0 & 3 & 93.0 \\
\hline Column 2 & 25.0 & 189.4 & 20.0 & 3 & 97.0 \\
\hline Column 3 & 50.0 & 189.4 & 20.0 & 3 & 96.5 \\
\hline
\end{tabular}

Results showed the use of Additive 1 in column leaching did not have any effect on the copper recovery or acid consumption. However, the percent of bed compaction experienced decreased with the use of Additive 1. This was beneficial as it indicated the agglomerates were strengthened with the use of the binder and would not degrade under high solution flows.

These previous studies by other investigators were used to base what types of binders should be tested further, and which binders were not reasonable to continue testing with. The explanation of binders chosen is given in the following section.

\section{Binder Evaluation}

One of the primary problems in using a binder or additive for copper heap leaching agglomeration is due to the acidic environment, which needs to be maintained to ensure high bacterial populations. Under the highly acidic conditions, most binders break down. Previously, there have been no standard procedures in which to test the selected binders. There is also no known economically feasible binder or additive which will work satisfactorily in an acidic environment. Due to the fact that there were no known binders which perform adequately, an array of various products including organic, inorganic, and polymeric binders needed to be tested. Testing a variety of products helped to determine what will help keep agglomerate strength.

\section{$\underline{\text { Soak Test }}$}

Before any binders were able to be tested, an experimental procedure needed to be developed. This procedure needed to give insight as to how well the agglomerates held together after being agglomerated with raffinate and/or various binders while being subjected to acidic conditions which would be found in a heap. The soak test was developed to accomplish this task.

For the soak test procedure, ore was agglomerated in a rotating drum with raffinate and a chosen binder. The addition of the binder helped to bond the fine particles to the coarser ones. It was then placed onto a Tyler 10 mesh screen and left to air dry, or cure. The screen was lowered into a sulfuric acid and water solution, simulating the acidic conditions which would be found in a heap. After 30 minutes, the acid solution was 
decanted and the fine material which had passed through the screen was collected, dried, and weighed. The procedure is diagramed in Figure 11.

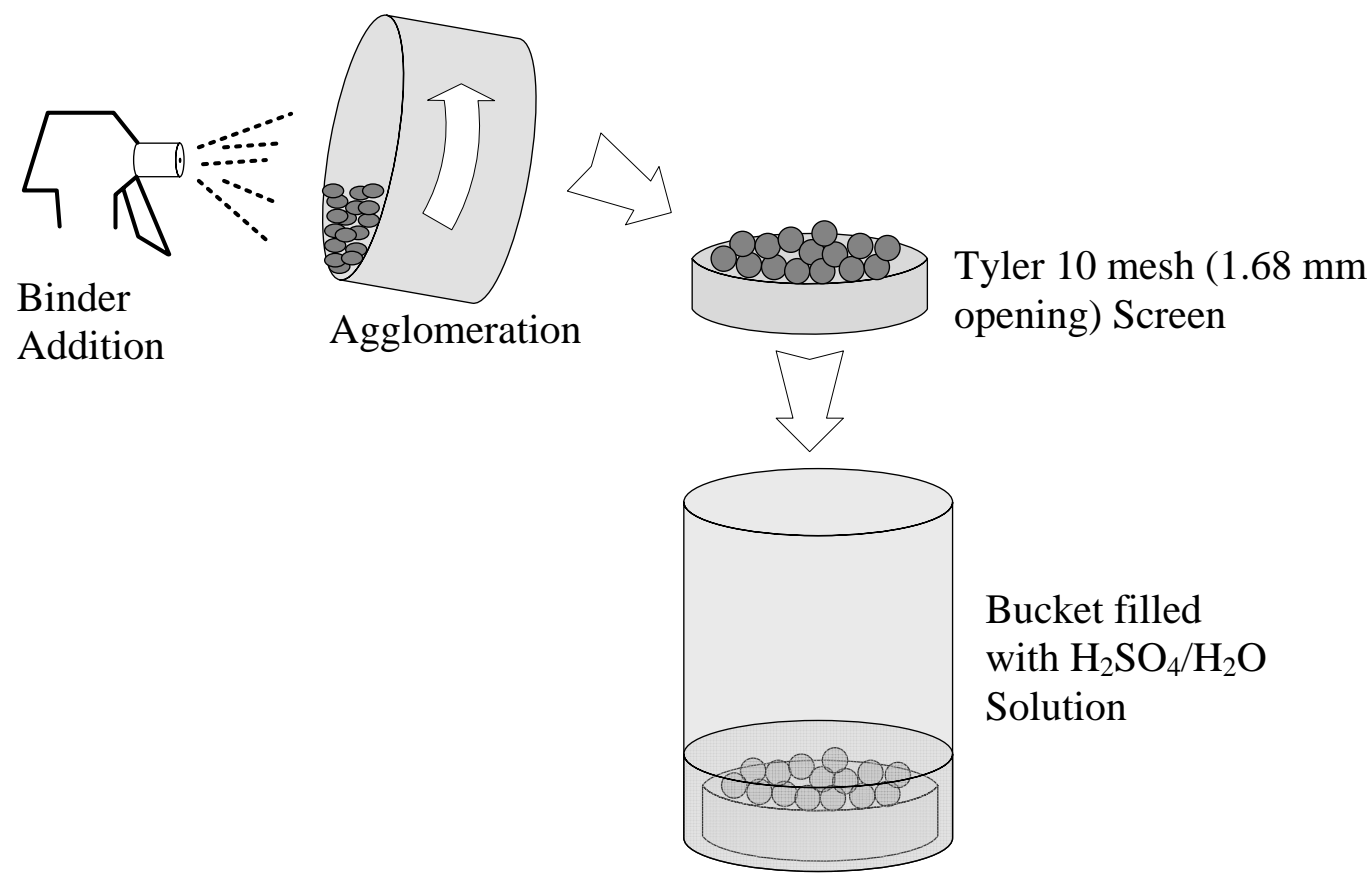

Figure 11: Soak Test Experimental Procedure

Binders were chosen on the basis of their potential ability to perform in an acidic environment. The binders chosen for agglomeration fell into three general classes: organic, inorganic, and polymeric. The binders which have been examined are presented in Table 3. These binders were chosen based on the following factors.

1. None of the organic binders which were previously tested would be beneficial to a copper heap leaching operation. Organic binders previously tested by other investigators for heap leaching operations, as listed in the Binders in Heap Leaching section, include agar, gelatin, gums, sodium carboxymethylcellulose, and starch. The agar was thought to hydrolyze in acid to form saccharide monomers which then reduced the adhesive properties. Both the gums and starch tested were also concluded to hydrolyze when coming in contact with sulfuric acid, reducing the binding properties. It was found that the sodium carboxymethylcellulose had negligible resistance to acid. Finally, the gelatin contained numbers of amino acids, several of which were derivatives of bactericides. Any chemical agents that were harmful to the bacterial were not applicable to the copper heap leaching situation.

Organic binders, such as modified cellulose and lignin, were chosen based on several factors. Both were integral parts of plant cell walls and were difficult to degrade. They were also used in paper making process binding to themselves to give strength. Lignin especially was a very abundant organic compound along with being highly hydrophilic, allowing it to be permeable to water. 
2. Inorganic binders previously tested by other investigators in heap leaching operations, as listed in the Binders in Heap Leaching section, include clays, iron (II) sulfate, silicic acid, sodium tripolyphosphate, calcium sulfate, and silicates. Many of the binders which have been tested in other applications either broke down resulting in solution channeling, or had poor acid tolerance.

Inorganic binders were tested based off of theoretical considerations. Binders such as sodium silicate were expected to react with the acid to form a silica gel which could act as a binder. Prior testing suggested additional agents may be mixed with silicates for better performance. Thus, sodium metasilicate was used, as it was readily available in the lab for testing. Additional inorganic binders with similar ability to dissolve in alkaline or neutral solution while precipitating on contact with acid could also be selected.

3. Polymer binders which have been tested, as listed in the Binders in Heap Leaching section, in other operations by other investigators include Acrylamide/acrylic acid copolymers, Extract-Ore 9560, polyacrylamide, and proprietary binder "Additive 1". Many of the results of these binders have not been published. Others, such as the Extract-Ore 9560 show marginal benefits.

Polymeric binders which have been reviewed by other investigators to have the ability to resist the action of acid were chosen based on what was readily available. Information from other investigators studies have talked about polyacrylamides and acrylamides, however not much had been published. Therefore, this was one family of polymers which was chosen. Polymer binders may also have the ability to bond to the hydrogen ions that adsorb onto the mineral surfaces.

The binders were judged on the percent of material which has passed through the 10 mesh screen, and is termed the amount of fines migrated. Fines migration is the only quantitative measurement which is able to be recorded from a soak test. The fines migration percentage can be calculated using Equation 7.

$$
\text { Fines Migration }=\frac{\text { Weight of ore migrated out of the sample }}{\text { Total weight of }-10 \text { mesh fines available in the sample }}
$$

Each agglomerated sample was also analyzed visually to give a comparison between tests. A visual progression of agglomerate deterioration in a soak test and the final fines collection are shown in Figure 12 \& 13. 


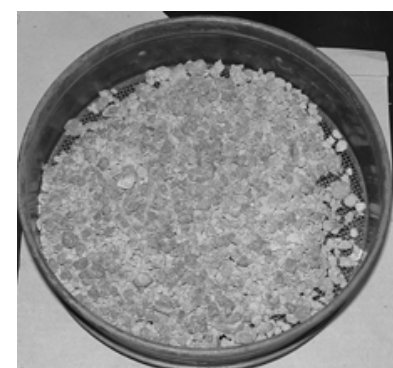

Agglomerates after 24 of cure time before soak test

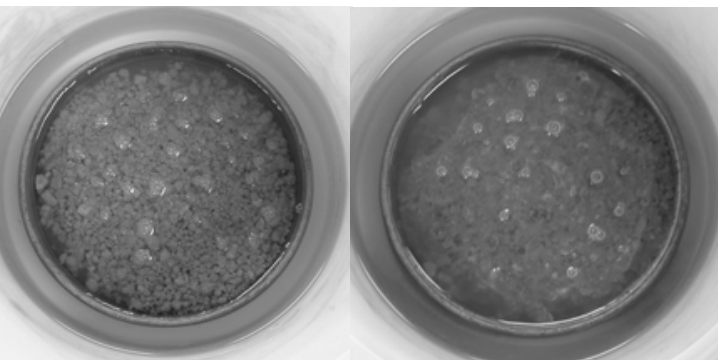

Agglomerates after initial immersion minutes of immersion

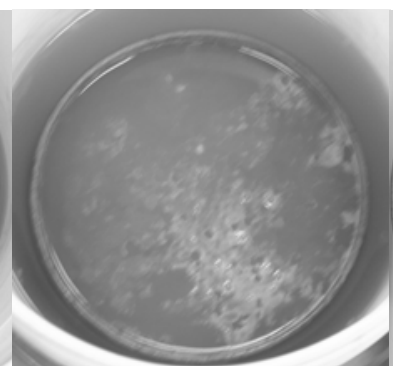

Agglomerates after 20 minutes of immersion

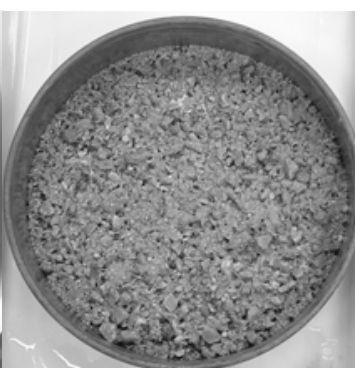

Broken down agglomerates after 30 minutes of immersion in soak test

Figure 12: Visual Deterioration of Agglomerates in Soak Test

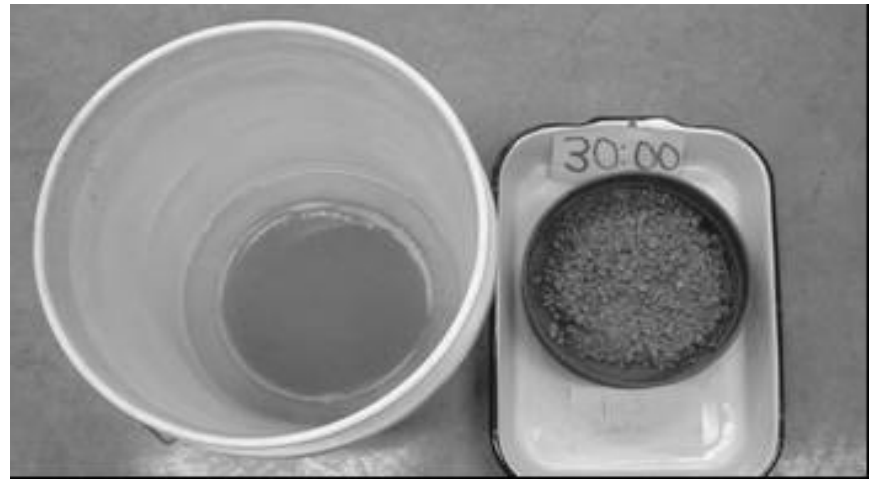

Figure 13: On the right is the Tyler 10 mesh screen holding the previously immersed agglomerates. The bucket on the left contains the fines which have been released due to the breakdown of the agglomerates.

The fines migration results are summarized in Figure 14. The numbers of tests performed per binder are listed along with the summarized fines migration results in Table 5. These results lead to the conclusion that the use of polymer binders resulted in better agglomerate strength. The results indicated that the polyvinyl acetate emulsion 1 , polyacrylamides, and the waste treatment additive showed the greatest decrease in the amount of fines released when compared to the baseline test where no binder other than raffinate was used. The agglomerates which used organic and inorganic additives all broke down during the soak test, resulting in high fines migration values, and therefore would not help to increase permeability any more so than agglomerating with only raffinate. 


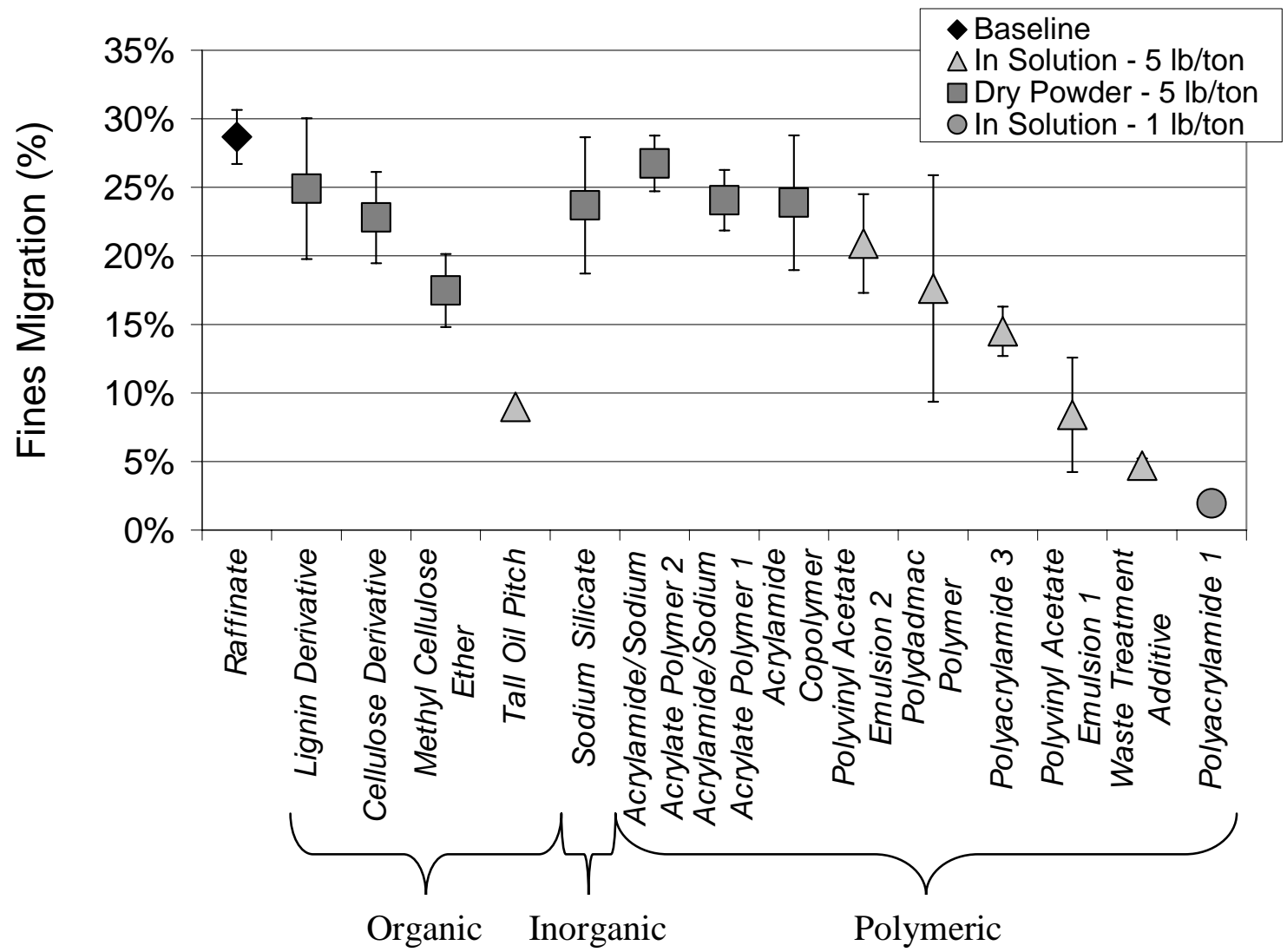

Figure 14: Fines Migration using Various Chemical Agents

Table 5: Fines Migration using Various Chemical Agents

\begin{tabular}{|c|c|c|c|c|c|}
\hline & \multirow{3}{*}{ Binder } & \multicolumn{2}{|c|}{ Percent of Fines Migration } & \multicolumn{2}{|c|}{ \# of Tests } \\
\hline & & \multicolumn{2}{|c|}{ Cure } & \multicolumn{2}{|c|}{ Cure } \\
\hline & & Dry & Solution & Dry & Solution \\
\hline & Raffinate & & $28.67 \% \pm 1.97 \%$ & & 2 \\
\hline \multirow{4}{*}{ Organic } & Lignin Derivative & $24.91 \% \pm 5.14 \%$ & $37.11 \%$ & 2 & 1 \\
\hline & Cellulose Derivative & $22.80 \% \pm 3.33 \%$ & & 2 & \\
\hline & Methyl Cellulose Ether & $17.48 \% \pm 2.66 \%$ & & 3 & \\
\hline & Tall Oil Pitch & & $8.67 \% \pm 0.45 \%$ & & 2 \\
\hline Inorganic & Sodium Silicate & $23.69 \% \pm 4.97 \%$ & $25.61 \% \pm 0.12 \%$ & 2 & 2 \\
\hline \multirow{9}{*}{ Polymeric } & Acrylamide/Sodium Acrylate Polymer 2 & $24.06 \% \pm 2.21 \%$ & & 3 & \\
\hline & Acrylamide/Sodium Acrylate Polymer 1 & $26.74 \% \pm 2.04 \%$ & & 3 & \\
\hline & Acrylamide Copolymer & $23.89 \% \pm 4.91 \%$ & & 3 & \\
\hline & Polyvinyl Acetate Emulsion 2 & & $20.91 \% \pm 3.61 \%$ & & 2 \\
\hline & Polydadmac Polymer & & $17.62 \% \pm 8.27 \%$ & & 3 \\
\hline & Polyacrylamide 3 & $20.83 \% \pm 6.36 \%$ & $14.50 \% \pm 1.80 \%$ & 3 & 2 \\
\hline & Polyvinyl Acetate Emulsion 1 & & $8.41 \% \pm 4.18 \%$ & & 2 \\
\hline & Waste Treatment Additive & & $4.70 \% \pm 0.52 \%$ & & 2 \\
\hline & Polyacrylamide 1 & $20.28 \% \pm 4.72 \%$ & $1.95 \% \pm 0.57 \%$ & 2 & 2 \\
\hline
\end{tabular}


The rate at which the agglomerates broke down was not only based on the binder being added, but was also found to be related to the moisture content of the agglomerates.

Several of the binders, which resulted in the least amount of fines in the soak tests, were tested again to determine the effects of moisture content. The results, shown in Figure 15, indicated that the wet agglomerates had better strength and released fewer fines, than the agglomerates which were allowed to dry overnight. The number of tests performed per binder, along with the results of the effect of cure time on fines migration, is summarized in Table 6 . All the binders performed better than the baseline test, which contained no binder, when the agglomerates were allowed cure time. It was concluded that some of the bonds between the ore and binder degrade during drying. Therefore, binders should not be tested while completely moist, as this is unrepresentative of what will be occurring in the heap, given that drying will occur during the lift stacking.

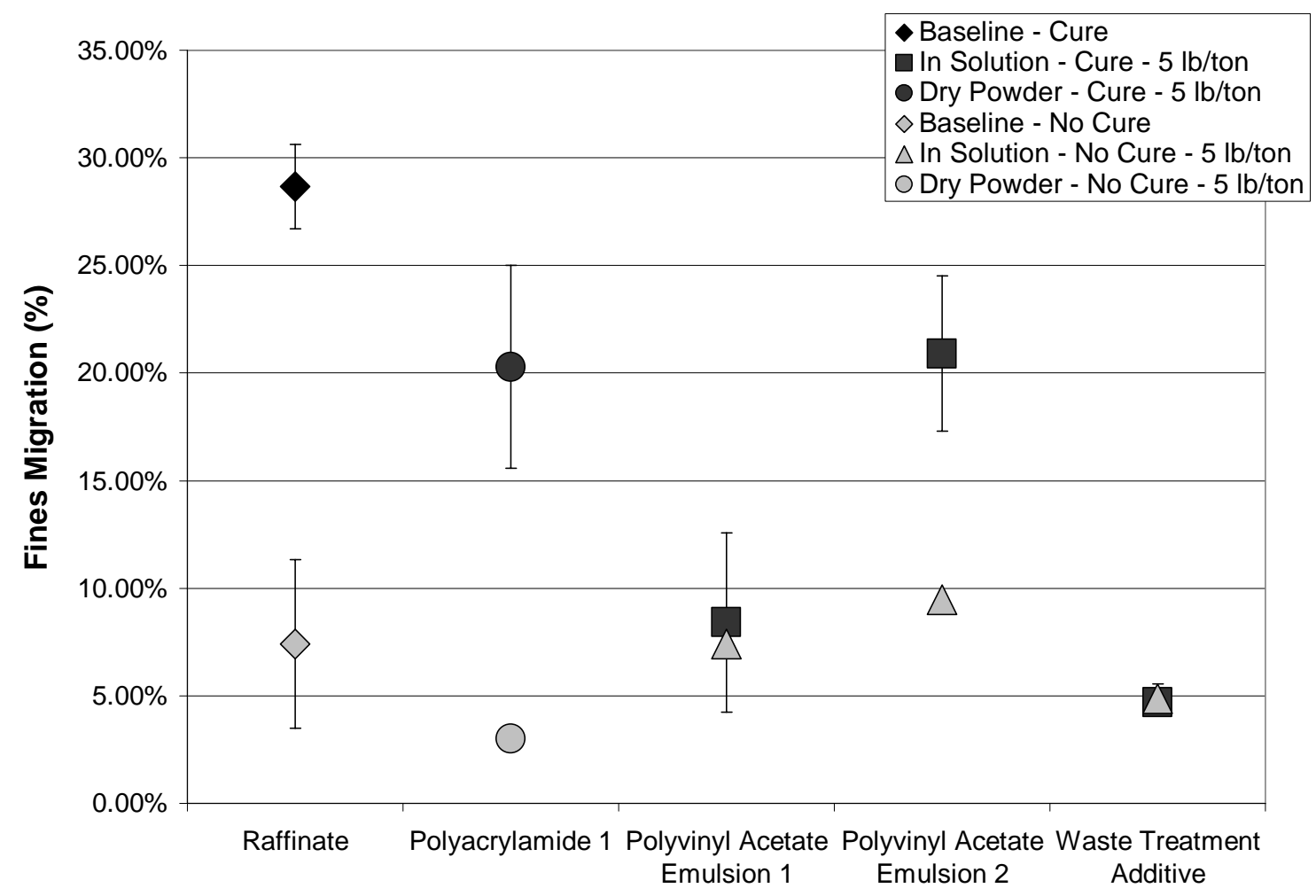

Figure 15: Effect of Cure Time on Fines Migration using Various Chemical Agents

Table 6: Effect of Cure Time on Fines Migration using Various Chemical Agents

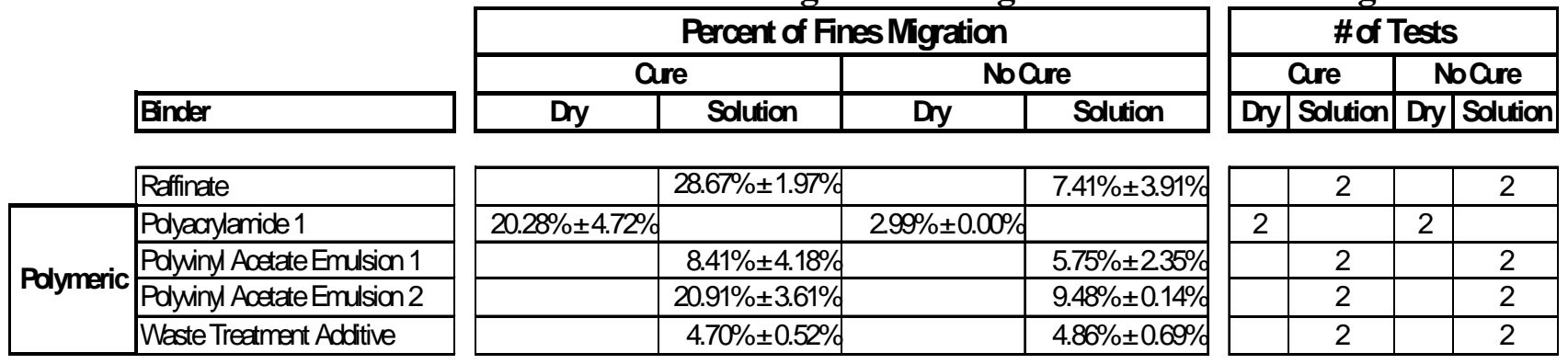




\section{Flooded Percolation Column Tests}

Several binders were able to withstand the acidic conditions that would be encountered in a leaching heap, as indicated by the soak test results. However, this did not necessarily mean that the use of these binders would result in increased permeability within the ore bed. Increased permeability is needed to ensure that the leach solution and air are able to flow evenly throughout the heap. Even flow will allow for all the ore to come in contact with the leach solution and air which will result in improved leaching kinetics and increase in metal recovery.

The degree of permeability within the ore bed can be related to the amount of void space within the heap. A greater void space would allow for an increased ability for the solution to flow freely through the heap. The change in amount of void space can be determined by calculating the bulk density of the ore bed, Equation 8 . Reporting the change in bulk density, Equation 9, eliminates differences due to variables such as differences in agglomerate size or differences in column loading. The void space within an ore body is important to obtain optimum kinetics of the leaching process by providing the area necessary for good liquid, solid, and gas interface.

$$
\begin{aligned}
& \rho_{\text {Bulk }}=\frac{\text { weight of ore }}{\text { volume of ore }} \\
& \Delta \rho_{\text {Bulk }}=\rho_{\text {Bulk Final }}-\rho_{\text {Bulk Initial }}
\end{aligned}
$$

Where:

$$
\rho=\text { density (ton } / \mathrm{yd}^{3} \text { ) }
$$

A high change in bulk density would indicate that the amount void spaces are decreasing during the leaching test. This would be a result of the agglomerates breaking down and compacting together. If the change in bulk density remains low, this indicates that the void spaces between agglomerates are maintained, however, it does not verify that the solution is able to flow freely through the ore bed. The ability for the solution to flow freely through the ore bed can be determined by calculating the hydraulic conductivity. Darcy's Equation, Equation 10, is used to determine the hydraulic conductivity of the system.

$$
Q=A * K * \frac{\Delta h}{L}
$$

Where:

$\mathrm{Q}=$ volumetric flow rate $\left(\mathrm{m}^{3} / \mathrm{s}\right)$

$\mathrm{L}=$ flow path length (m)

$A=$ flow area perpendicular to $\mathrm{L}\left(\mathrm{m}^{2}\right)$

$\Delta \mathrm{h}=$ change in hydraulic head (m)

$\mathrm{K}=$ hydraulic conductivity $(\mathrm{m} / \mathrm{s})$ 
The extent of breakdown of the agglomerates can also be quantified by the percentage of fines which have migrated. This can be concluded by comparing the amount of fine material which has passed through the ore bed, with the amount of that same size material which was initially put into the system. A good binder used for agglomeration addressed these issues by keeping fines bound together, creating a more uniform size distribution and producing minimal fines migration.

Determining the degree of permeability allowed the binders to be compared, to decide whether the binders were helping to increase agglomerate strength and the ability for solution to flow through the heap. However, a standard procedure to calculate the bulk density and hydraulic conductivity had not been developed. Therefore, the flooded column test was designed and constructed to test these parameters.

The flooded columns test apparatuses, shown in Figure 16, were assembled.

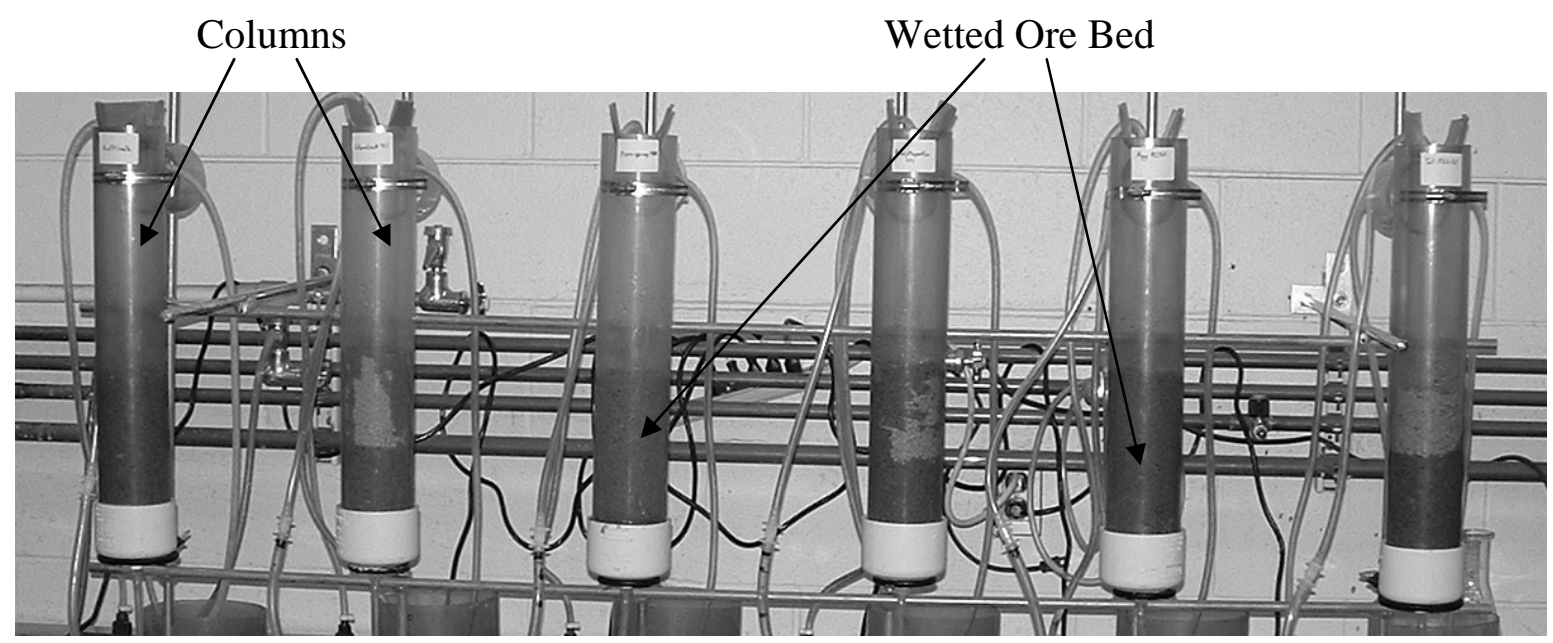

Figure 16: Flooded Test Columns

The ore is agglomerated with raffinate and a chosen binder. The ore is allowed to air dry, or cure. After drying, the agglomerated ore is then transferred to a column. Leach solution is dripped onto the top of the column, where it begins to slowly flood the column. The solution exits the column through the overflow system. Figure 17 outlines this process. 


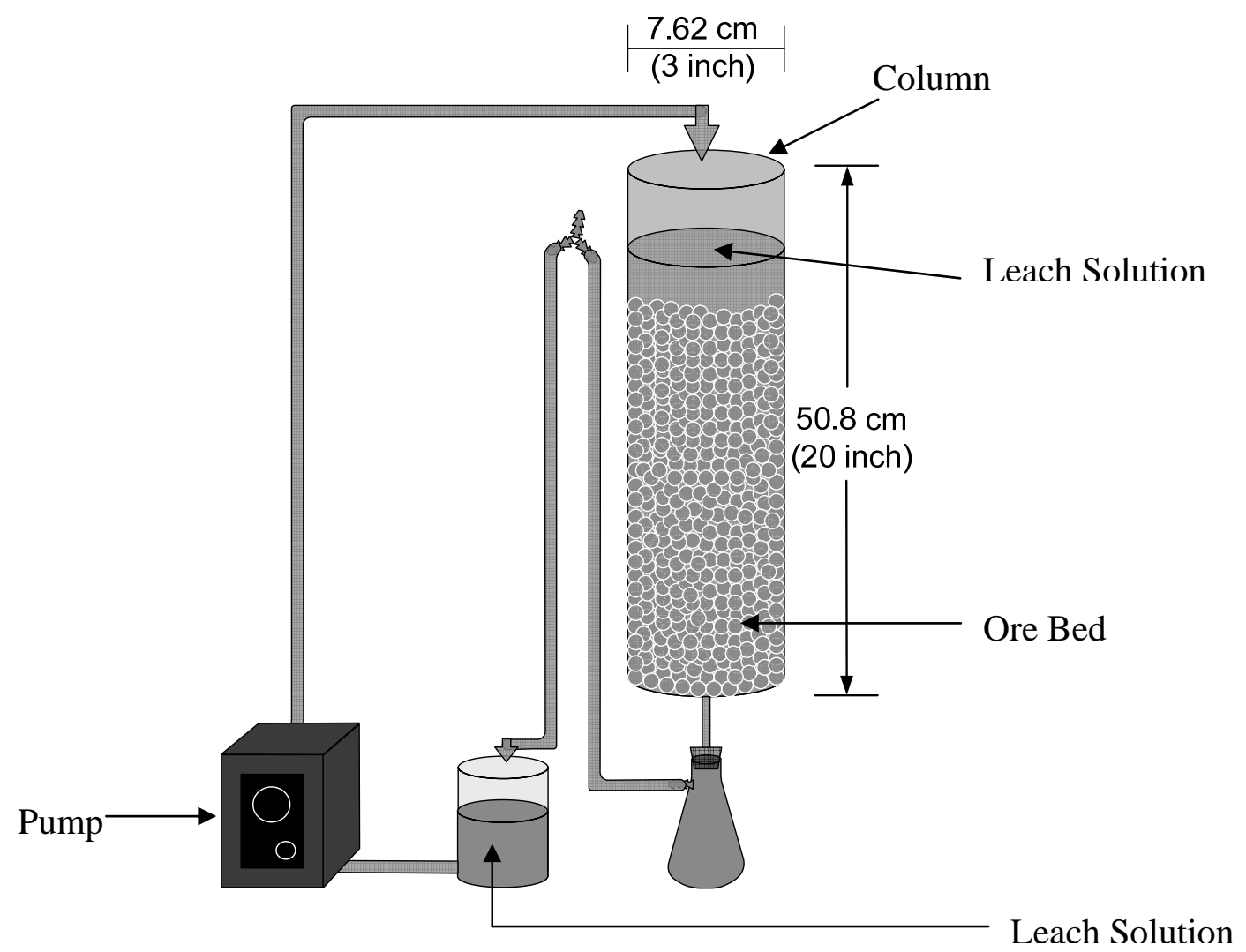

Figure 17: Schematic of Flooded Column Test

The polymer binders which improved the strength of the agglomerates under acidic conditions in the soak test were then tested in the flooded column. Fines migration results, Figure 18, indicated that the all of the synthetic binders tested had a lower percentage of fines migration than the baseline test. This indicates that the agglomerates that were made with a binder had a lower tendency to breakdown. The tall oil pitch and the waste treatment additive agglomerates had the lowest amount of fines migration. 


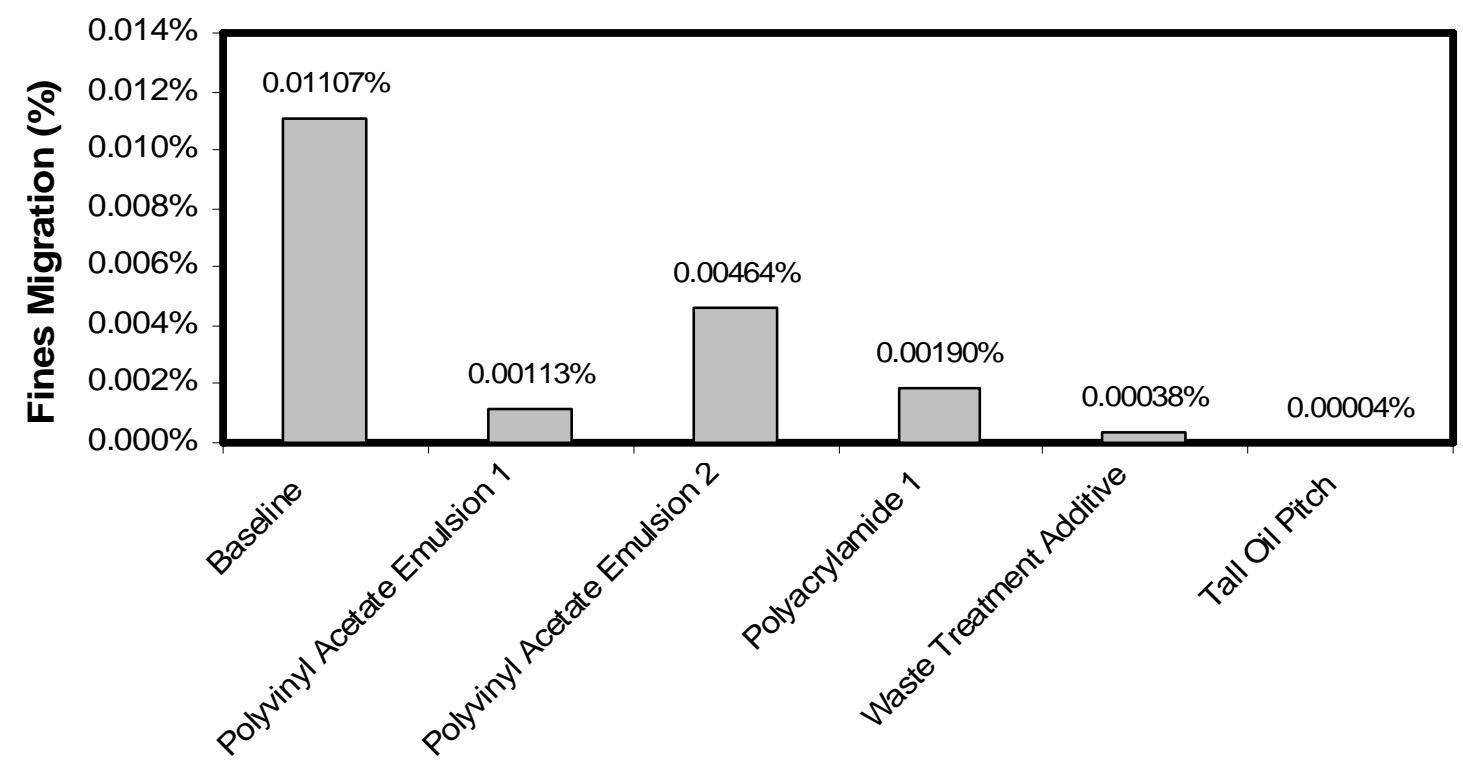

Figure 18: Ratio of Fines in Flooded Column Tests

The ore bulk densities varied for these five particular binders and raffinate. A higher change in bulk density indicated there was a decrease in the amount of volume that the mass of ore in the flooded columns occupied. A higher bulk density indicates that there is more compaction of the ore in the column due to the agglomerate breakdown. This compaction leads to a decrease in void space within the ore bed. Solution and air flow is impeded if there is not enough void space within the heap. The tall oil pitch had the least amount of fines released. It also had the lowest change in bulk density of the binders tested. Figure 19 shows the ore bulk density with time for the various agglomeration binders. 


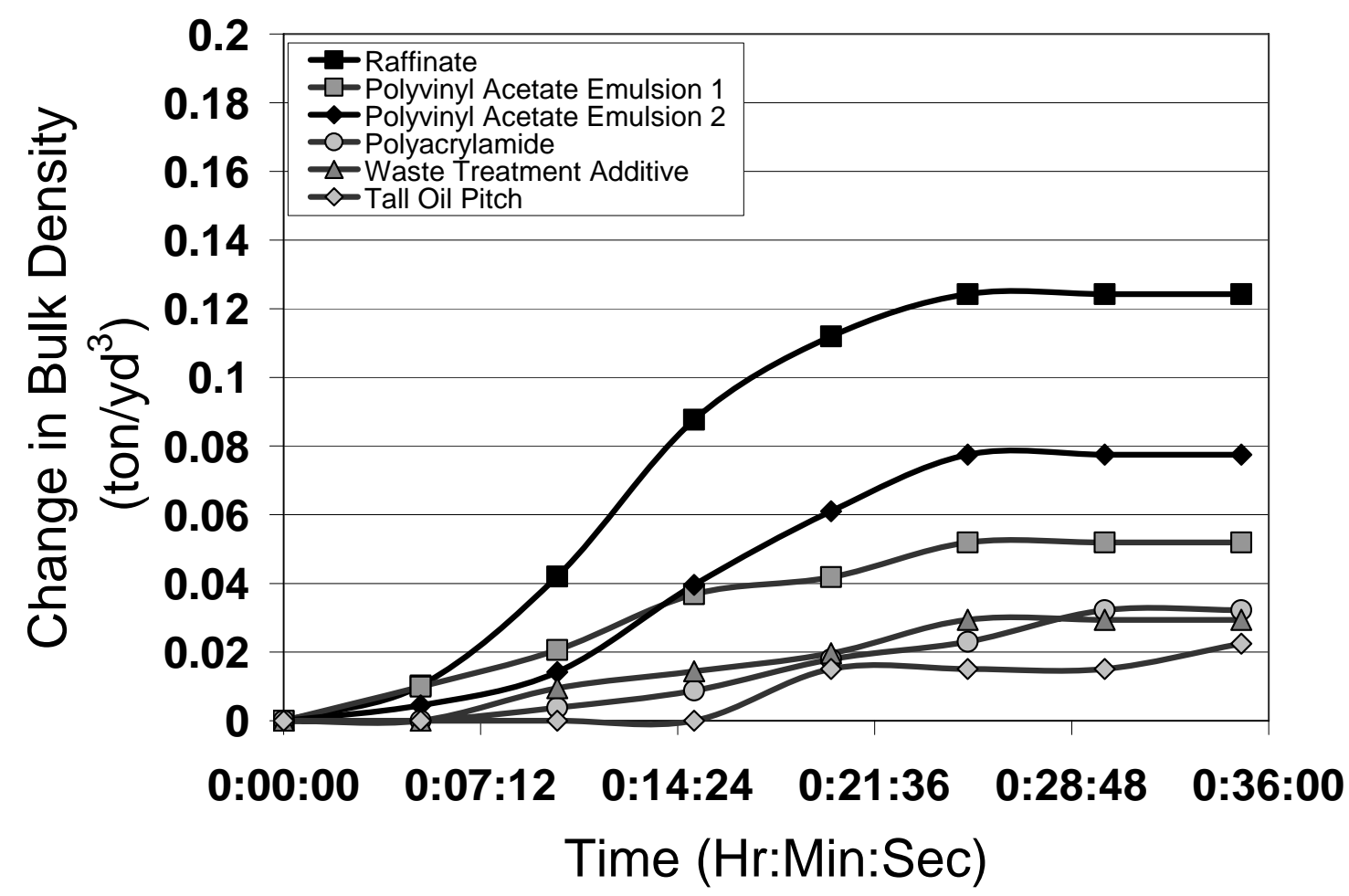

Figure 19: Change in Ore Bulk Density vs. Time for Best Performing Binders

The column agglomerated with tall oil pitch had the smallest change in bulk density. These agglomerates also never visually broke down. The agglomerates in the raffinate \& polyvinyl acetate emulsion 2 columns were able to be seen breaking down. This was shown quantitatively by high changes in bulk density and a high percentage of fines migration.

Although the void space is not decreasing as greatly with the use of the binders, the ability for the solution to flow through the ore bed, hydraulic conductivity, still needed to be determined. If a particular binder has a high hydraulic conductivity this means the reagents can be carried through the heap easily, which allows for better leach kinetics.

Measurements to determine conductivity were taken on the same five binders and raffinate, as analyzed for bulk density and fines migration. The summary of the results are shown in Figure 20. The polyacrylamide showed the highest conductivity, which means the solution had an easier time flowing through the ore bed. The polyvinyl acetate emulsion 2 produced the lowest hydraulic conductivities out of the five binders. It also had the highest fines migration rate and the highest change in bulk density out of all the binders. This indicates that the agglomerates were deteriorating, causing compaction of the ore bed and an increase in bulk density. This along with the fine material which was released from the agglomerates resulted in solution not being able to flow easily. However, all binders had higher conductivities than the ore agglomerated with raffinate only. 


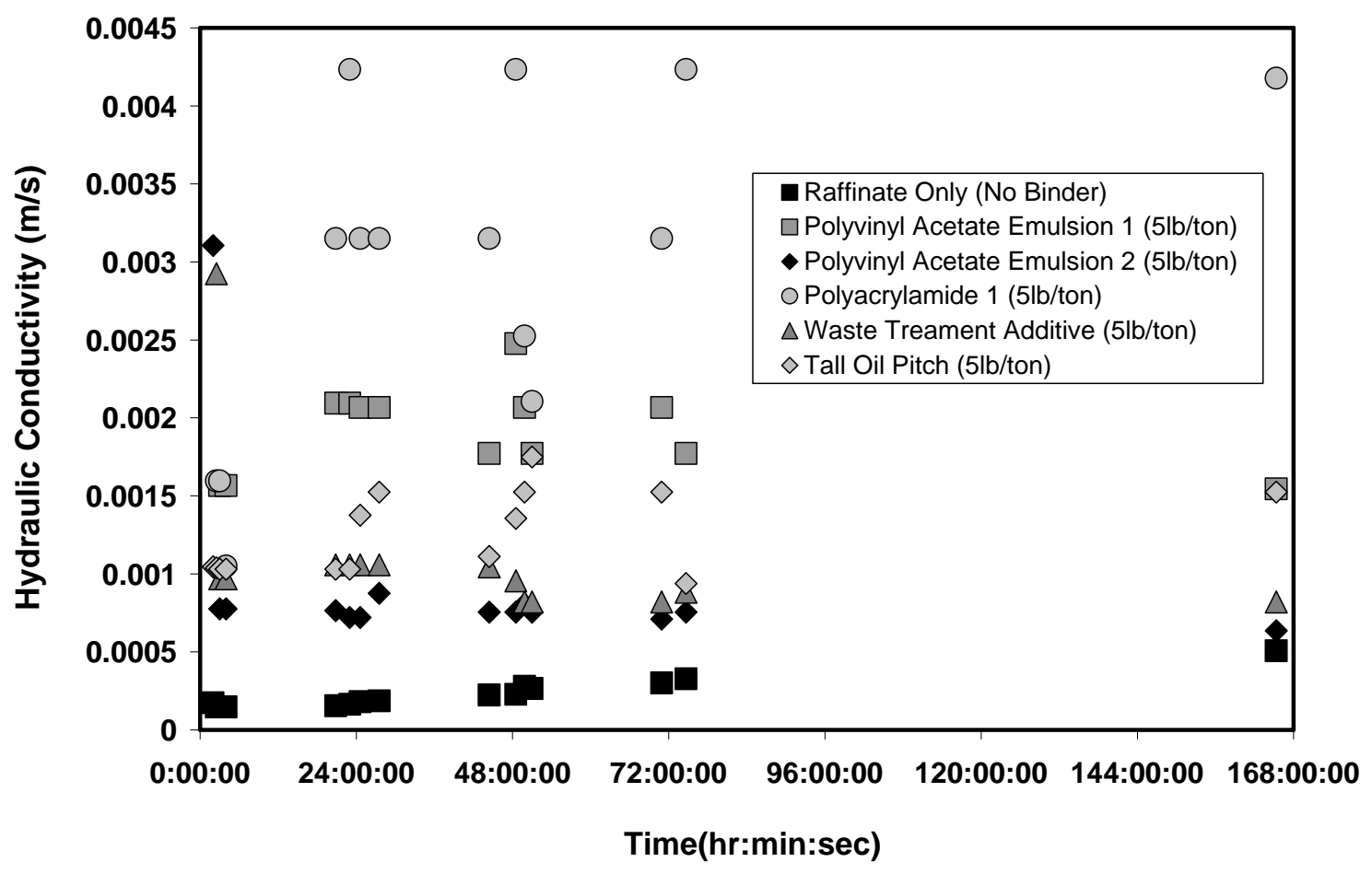

Figure 20: Hydraulic Conductivity for the Best Performing Binders

Initially, one flow measurement was taken at the beginning of a test. However, the flow rates of the pumps cycle up and down slightly due to the pumps heating up and not performing consistently. The hydraulic conductivity measurements are based off of the solution flow rate resulting in a fluctuation within the data. All remaining tests included a flow rate measurement taken for each hydraulic conductivity point to eliminate the variation.

For comparison purposes all the agglomerates were prepared using a binder addition rate of $5 \mathrm{lb}$ of binder per ton of ore. However, this may not be the optimum dosage rate for each binder. A greater or less quantity of binder may actually allow it to produce more stable agglomerates. To determine the optimum binder addition rate, multiple flooded columns were run at various binder addition rates. Hydraulic conductivity and bulk density measurements were used to determine the optimum addition rates. Four binders addition rates, polyvinyl acetate 1 , polyacrylamide, waste treatment additive, and tall oil pitch, have been optimized.

The optimum dosage was determined by looking at the binder dosage rate when the hydraulic conductivity first began to reach a state where there was no longer a significant increase in hydraulic conductivity with increasing binder addition. The change in bulk density also showed a leveling trend around this same addition rate. The optimum binder dosages were determined from the hydraulic conductivity and bulk density results shown for the four binders which have been tested in Figures 21 through 28. 


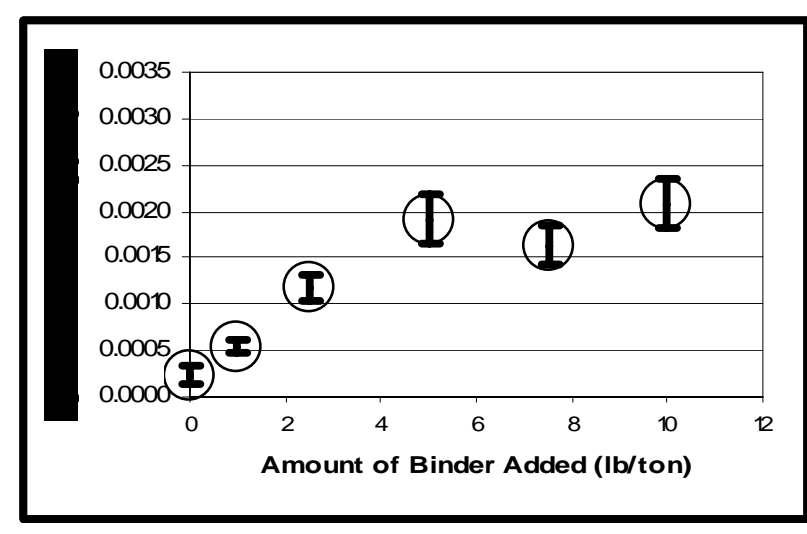

Figure 21: Flooded Column Hydraulic Conductivity Evaluation for the Polyvinyl Acetate 1

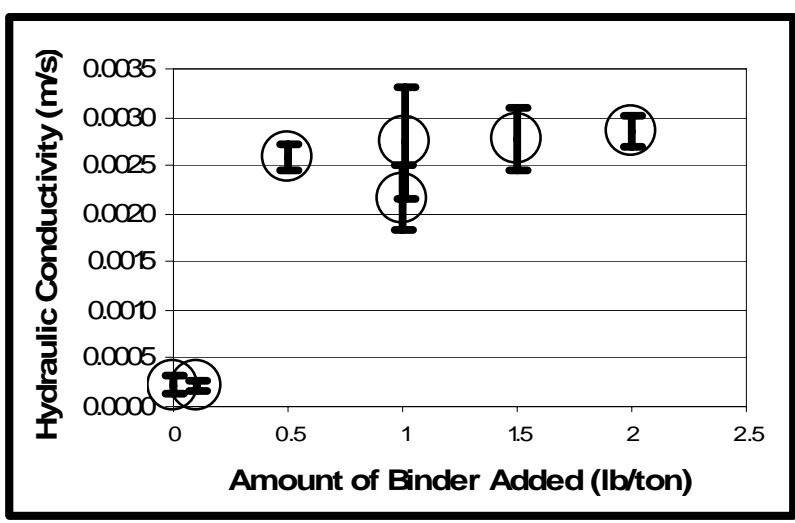

Figure 23: Flooded Column Hydraulic

Conductivity Evaluation for the

Polyacrylamide 1

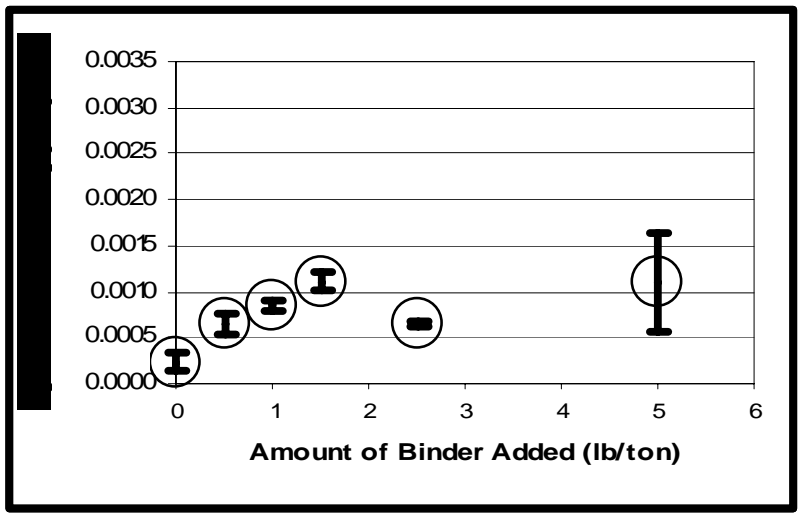

Figure 25: Flooded Column Hydraulic Conductivity Evaluation for the Waste Treatment Additive

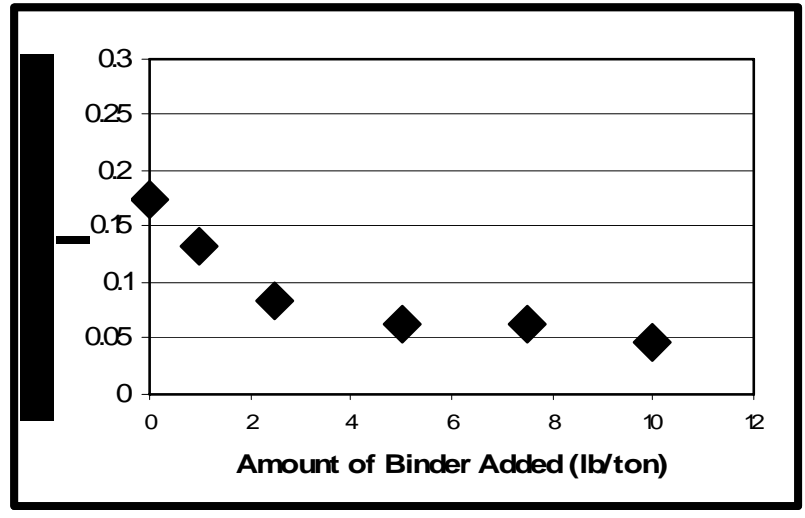

Figure 22: Flooded Column Bulk

Density Evaluation for the

Polyvinyl Acetate 1

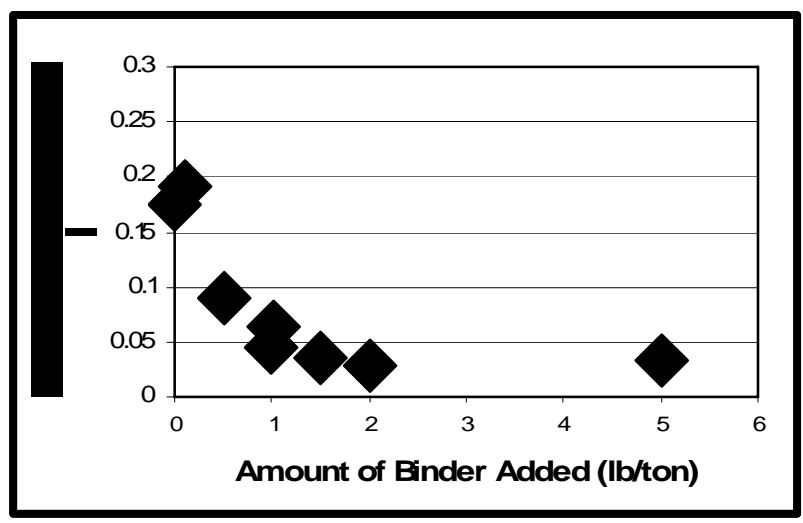

Figure 24: Flooded Column Bulk Density Evaluation for the Polyacrylamide 1

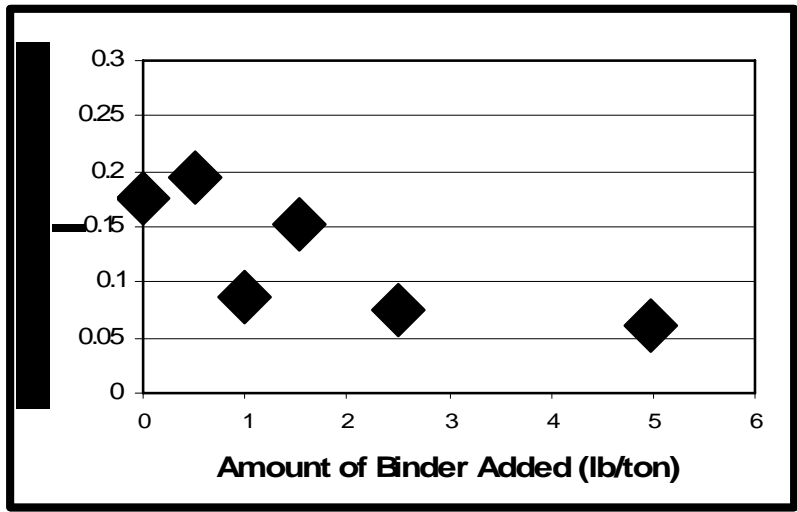

Figure 26: Flooded Column Bulk

Density Evaluation for the Waste Treatment Additive 


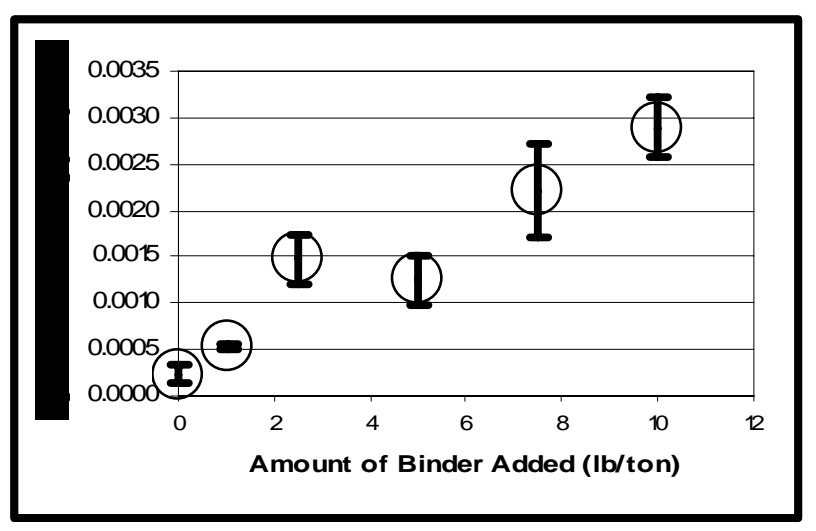

Figure 27: Flooded Column Hydraulic Conductivity Evaluation for the Tall Oil Pitch

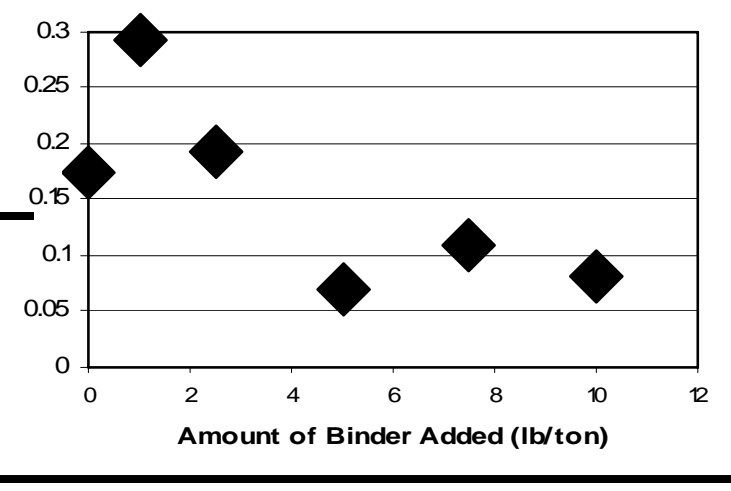

Figure 28: Flooded Column Bulk Density Evaluation for the Tall Oil Pitch

From these results it was determined that the polyvinyl acetate 1 , polyacrylamide 1 , and the waste treatment additive had optimum binder dosage rates of $5 \mathrm{lb} / \mathrm{ton}, 1 \mathrm{lb} / \mathrm{ton}$, and $1.5 \mathrm{lb} /$ ton respectively. The ease of solution flow kept increasing with increasing tall oil pitch binder dosage rates. However, the use of this binder will become uneconomical at such high binder addition rates. Therefore, an optimum dosage rate for the tall oil pitch was determined to be $6 \mathrm{lb} / \mathrm{ton}$, as this is where the change in bulk density began to become stable with increasing binder dosage.

The flooded column test was used to analyze the changes in solution flow, void space, and migration of fine material with the use of several different binders. However, accurate copper recovery data could not be collected from these columns as factors such as solution flow and ore top size are not accurate as to what would be found in a heap. Therefore, as the columns would not be used for copper recovery data, they were not equipped with any air injection, which would play a major role in the extent of copper recovery obtained, as described in Equation 3.

\section{Long-Term Leach Columns}

To determine whether the use of binders showed improved copper recoveries, the industrial heap needed to be simulated on a scaled down laboratory set-up. This would also allow the binder affect on the bacterial populations to be monitored. An experimental apparatus was created to perform this task.

A long-term leach column was designed and constructed to carry out this simulation. The columns, shown below in Figure 29, were created to simulate a leach heap. Only the best binders will be tested in these columns, as the leach cycle is 180 days. Six of these columns have been built in the Michigan Technological University Laboratory. The columns height, air flow rates, and solution flow rates were all scaled down from the values that were currently being used in industry. One difficulty with this experimental set-up was that factors such as channeling, where the solution flows directly down one path without spreading evenly over the ore body, are not accurately represented, as the 
space for this to occur is limited to $15.24 \mathrm{~cm}$ (6 inches) rather than the whole length of a heap. Due to this factor, the tests will only indicate whether the binders are having a negative effect on copper recovery and bacterial growth.

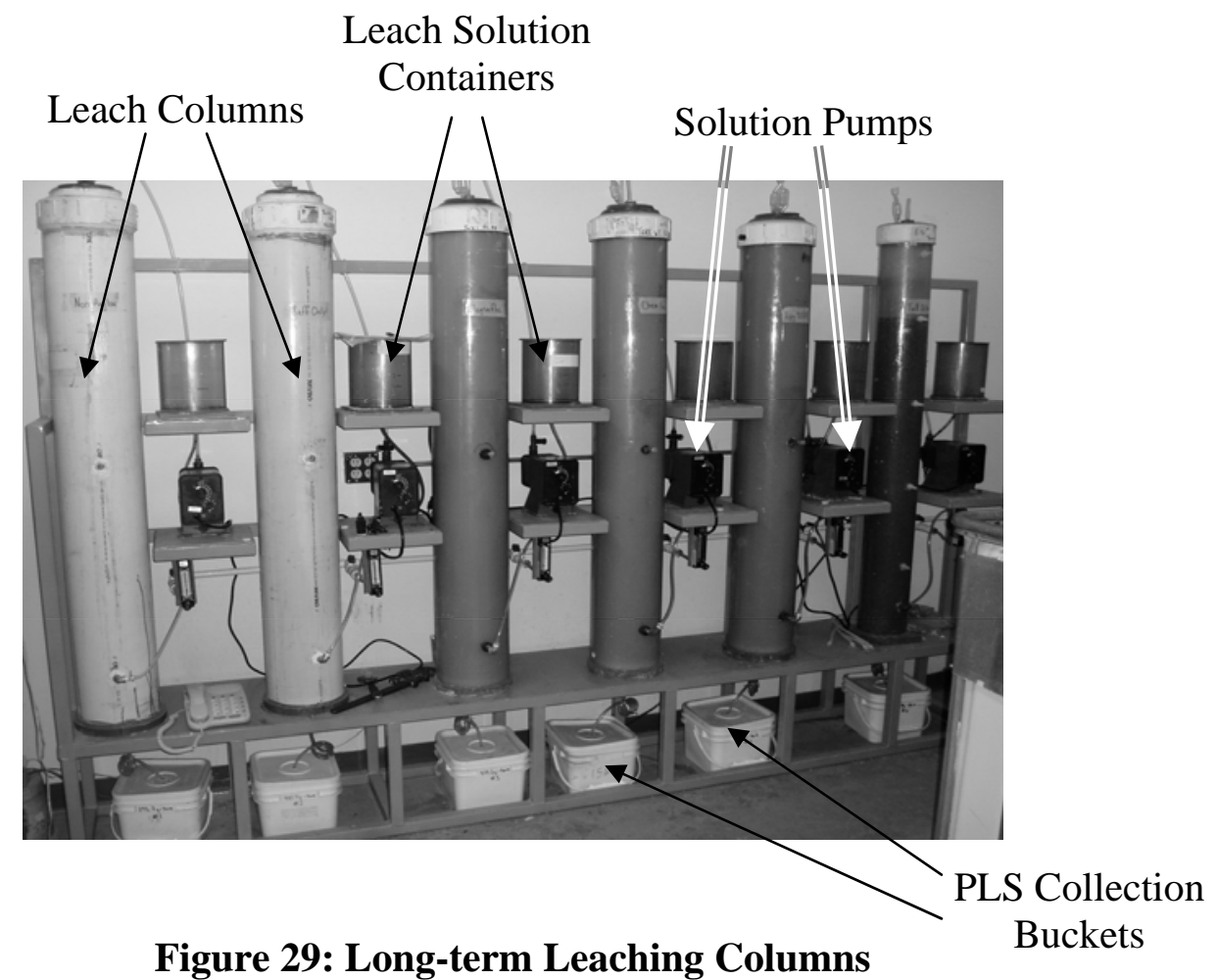

The ore used is agglomerated and allowed to air dry, or cure, for at least 72 hours. This time is representative of the approximate time it takes for a lift to be created. The ore is then distributed into the column, where it is capped to allow for a controlled environment. An air line is connected to the base of the column. The raffinate is pumped into the top of the column where it is dripped on the ore. Raffinate solution percolates slowly through the column, and is collected in a bucket below, as shown in Figure 30. The solution collected is called pregnant leach solution (PLS), and is later tested for copper and iron recovery along with $\mathrm{pH}$, oxidation/reduction potential (ORP), and temperature. 


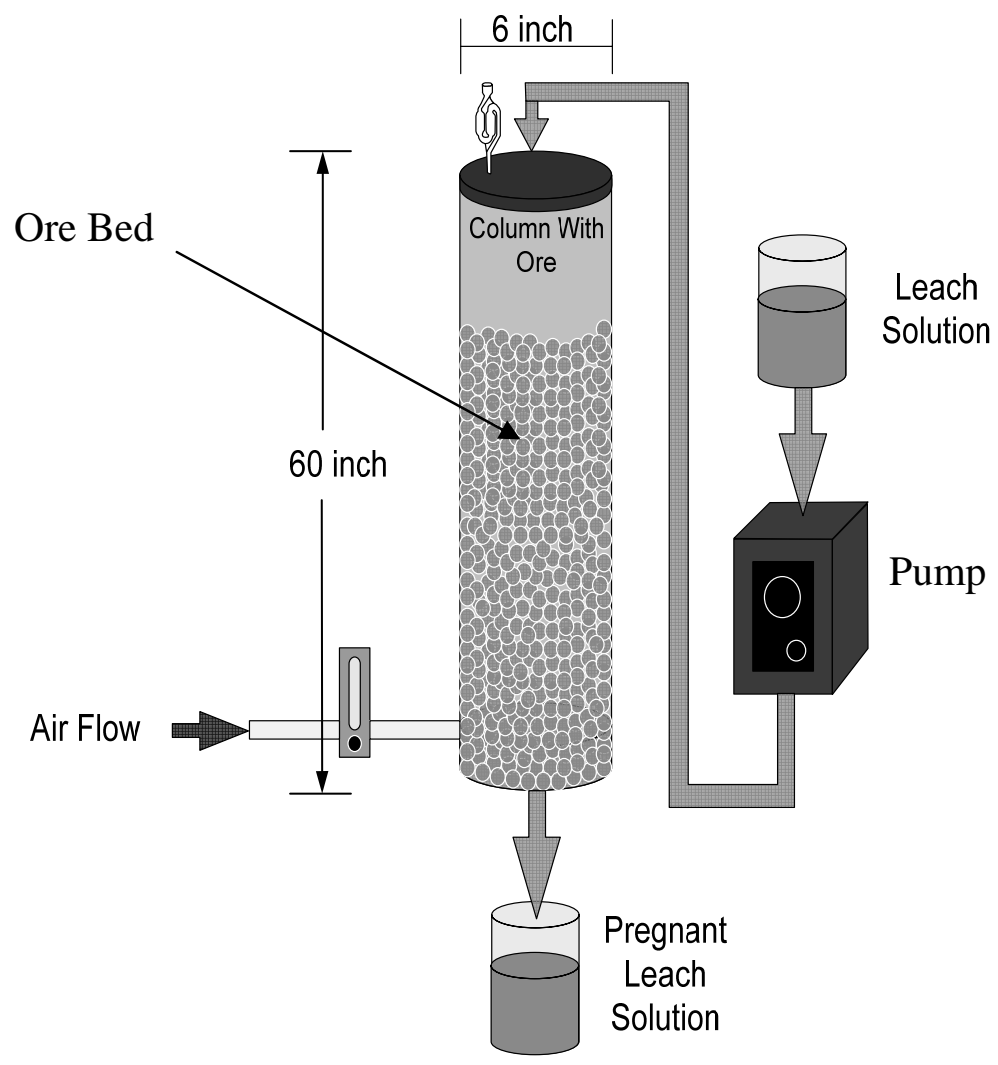

Figure 30: Schematic of Leach Testing Column

Five of these columns have been run at Michigan Technological University. These five columns included one with ore where the ore had been agglomerated with raffinate (leach solution) only, and the remaining four had ore agglomerated with the four synthetic binders which have proven to improve agglomerate stability in the soak \& flooded column tests. These synthetic binders include the polyacrylamide, polyvinyl acetate emulsion 1, tall oil pitch, and the waste treatment additive.

The copper recoveries, shown in Figure 31, indicated that there was no adverse effect to the leaching process by using these binders in agglomeration. 


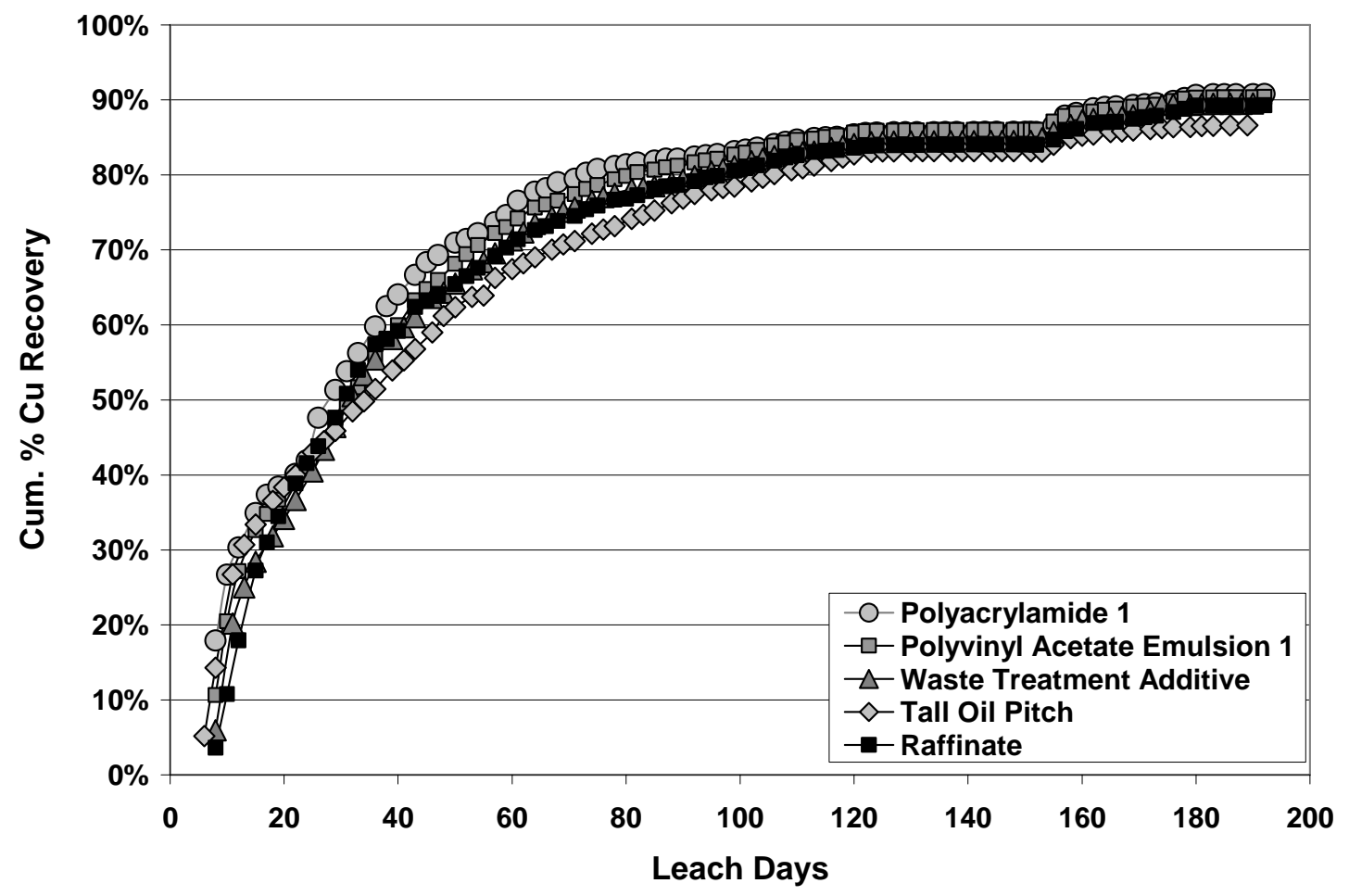

Figure 31: MTU Long-Term Leach Column Copper Recoveries

The copper recoveries of all the columns with ore agglomerated with a synthetic binder were within $\pm 5 \%$ of the raffinate agglomerated test. This difference may be contributed by experimental error. The long-term leach columns were duplicated concurrently at our industrial partners copper heap leaching operation in Arizona. Both the Arizona location and Michigan Technological University (MTU) ran columns using the same binders and ore from the same split from the Arizona industrial process circuit. More data is still to be collected before a final comparison can take place between the two locations.

The bacteria populations in the column are important. From Equation 3, it is shown that the bacteria helps convert the iron $\left(\mathrm{Fe}^{2+}\right)$ back into iron $\left(\mathrm{Fe}^{3+}\right)$, which is necessary to help with the continuing extraction of copper from the chalcocite ore. The bacterial population can be related to the oxidation/reduction potential (ORP). A low ORP indicated a greater concentration of ferrous iron in the system. A higher ORP indicated there was a greater amount of ferric iron in the system. A high ORP is desired, as this means there is plenty of reactant, or ferric iron, in the system. This would show there was a high enough bacterial population to convert all the ferrous iron back to ferric, to allow the chalcocite reactions to continue.

The oxidation/reduction potential results from the long-term leach columns, Figure 32, show that the bacterial populations for those columns agglomerated with synthetic binders were greater than the raffinate agglomerated column for most of the leach cycle. At the beginning of the leach cycle the ORP's are low. As the leach cycle goes on, the ORP increases. At this point the amount of iron $\left(\mathrm{Fe}^{3+}\right)$ in the system increases 
accordingly. This means the use of the binders does not interfere with the bacterial populations, in fact they seem to promote bacterial growth over the raffinate agglomerated column. High bacterial populations are necessary to make sure there is enough feed material to enable the leach kinetics to progress.

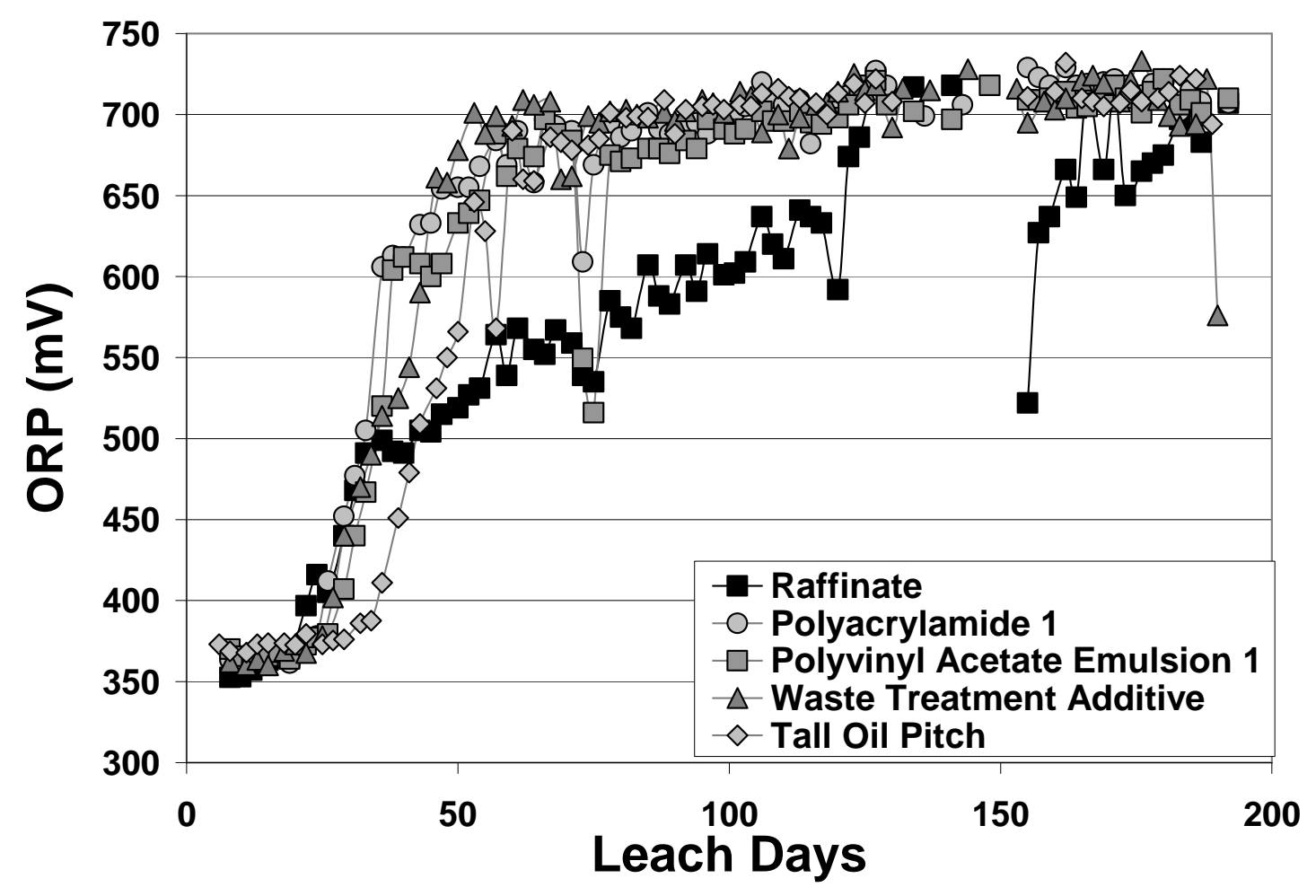

Figure 32: Oxidation/Reduction Potential results from MTU long-term leach columns

The rest period in the leach cycle occurred between days 120 and 150. At this point no leach solution was being added to the columns. At the end of this rest period, the ORP's for the raffinate agglomerated columns fell considerably. This meant the amount of ferric iron in the system was decreasing and the amount of ferrous iron was increasing. If the low ORP's were experienced for a long period of time, this would begin to affect the leaching kinetics, given in Equations 1, 2, and 3, and eventually result in a decreased copper recovery.

The stability of the agglomerates throughout the long-term leach column tests were evaluated by comparing the bulk density, or slump, of the ore bed in each column. Figure 33 shows the overall change in bulk density results for the long-term leach columns. 


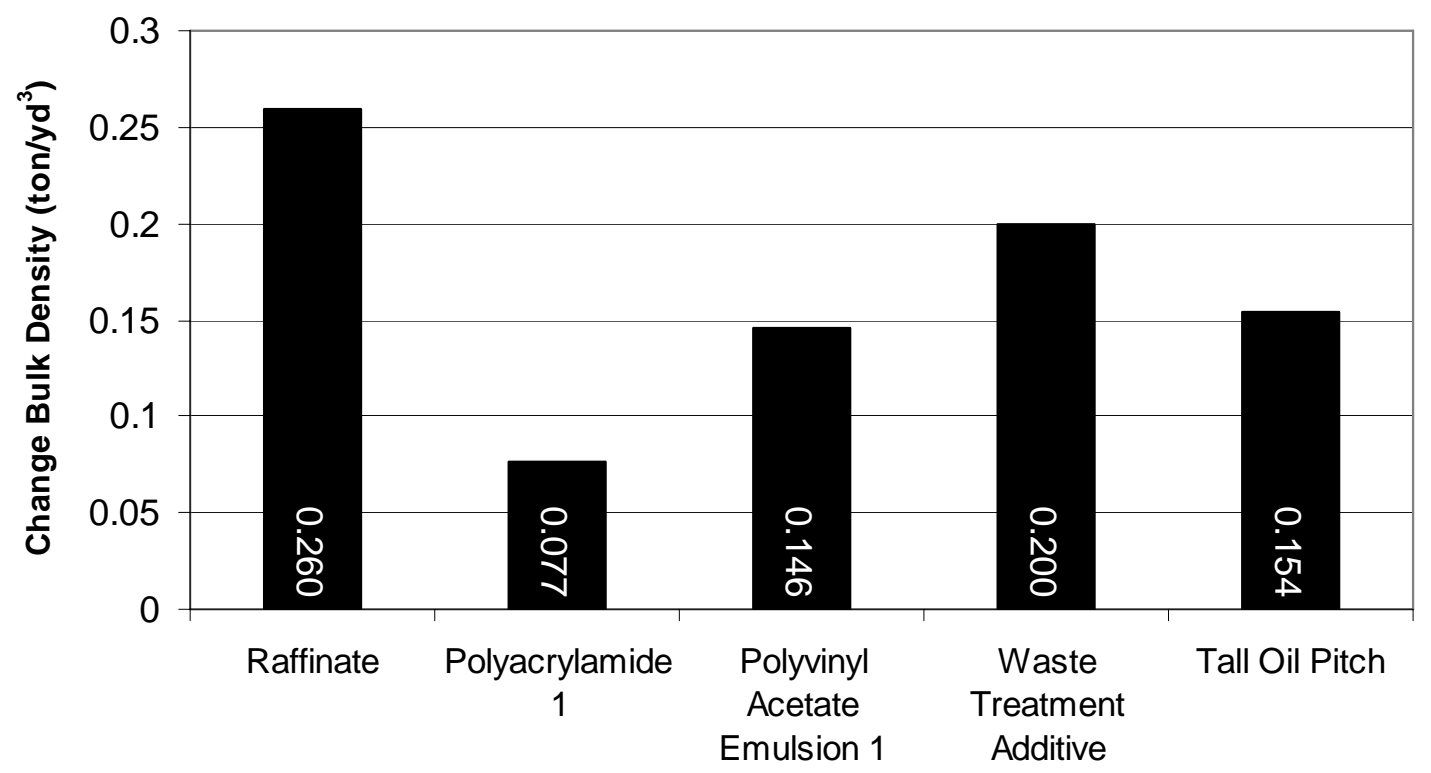

Figure 33: Total change in bulk density for various binders over the entire leach cycle

The polyacrylamide had the lowest change in bulk density measurements of the binders tested. This indicated that the agglomerates in this column had greater stability, and were less likely to break apart over time. This also means the void spaces within the ore bed were maintained, which in the long run would allow for better solution flow. The change in bulk density of the raffinate agglomerated column was the highest. In the column the agglomerates deteriorated more.

Although the long-term leach columns are a useful way to determine if there are any negative effects by agglomerating with a binder, they are unable to take into account all the factors which would occur in an industrial sized heap. In a heap, the ore is stacked into approximately 22 foot high lifts. The long-term leach columns are only taking into account the top 5 feet of ore in the heap. The breakdown in agglomerates and decrease in void space in an industrial heap can partly be contributed to the weight of the ore alone and by trucks driving on the top surface. Compaction due to these factors was not able to be taken into account in the long-term leach columns. It is important to determine if the use of a binder will be beneficial when the heap is under compaction.

Testing was completed to evaluate the binders under compression. This data was used to compare the different binders. This gave a better understanding of the additional benefits of each binder in a heap leach setting.

To test the binders under compaction a special apparatus was designed and built. This apparatus is currently in the process of becoming fully patented by the MTU investigators of this project. Currently, MTU holds a provisional patent, serial number US60/750,236 on the apparatus. The apparatus was similar to the flooded column test, allowing for the 
same measurements to be made, but under a pressure that would simulate what an actual heap was likely to have at a distance of 10 feet under the surface. The flow rates used for these test were more than 10 times that of the normal field flows. The high flow rates gave a much harsher environment showing longer term effects in a shorter period of time. The compaction, however, is far less than what an actual heap would be placed under.

Experiments were performed on non-agglomerated ore, ore agglomerated with raffinate, and ore agglomerated with the four binders used in the long-term leach columns. The trial where the ore was agglomerated with only raffinate yielded some interesting results, illustrated in Figure 34, when comparing bulk density as a function of leach time for the three raffinate agglomerated columns. The paths taken to achieve these bulk densities are somewhat different. Three distinct scenarios can be realized within this set of data.

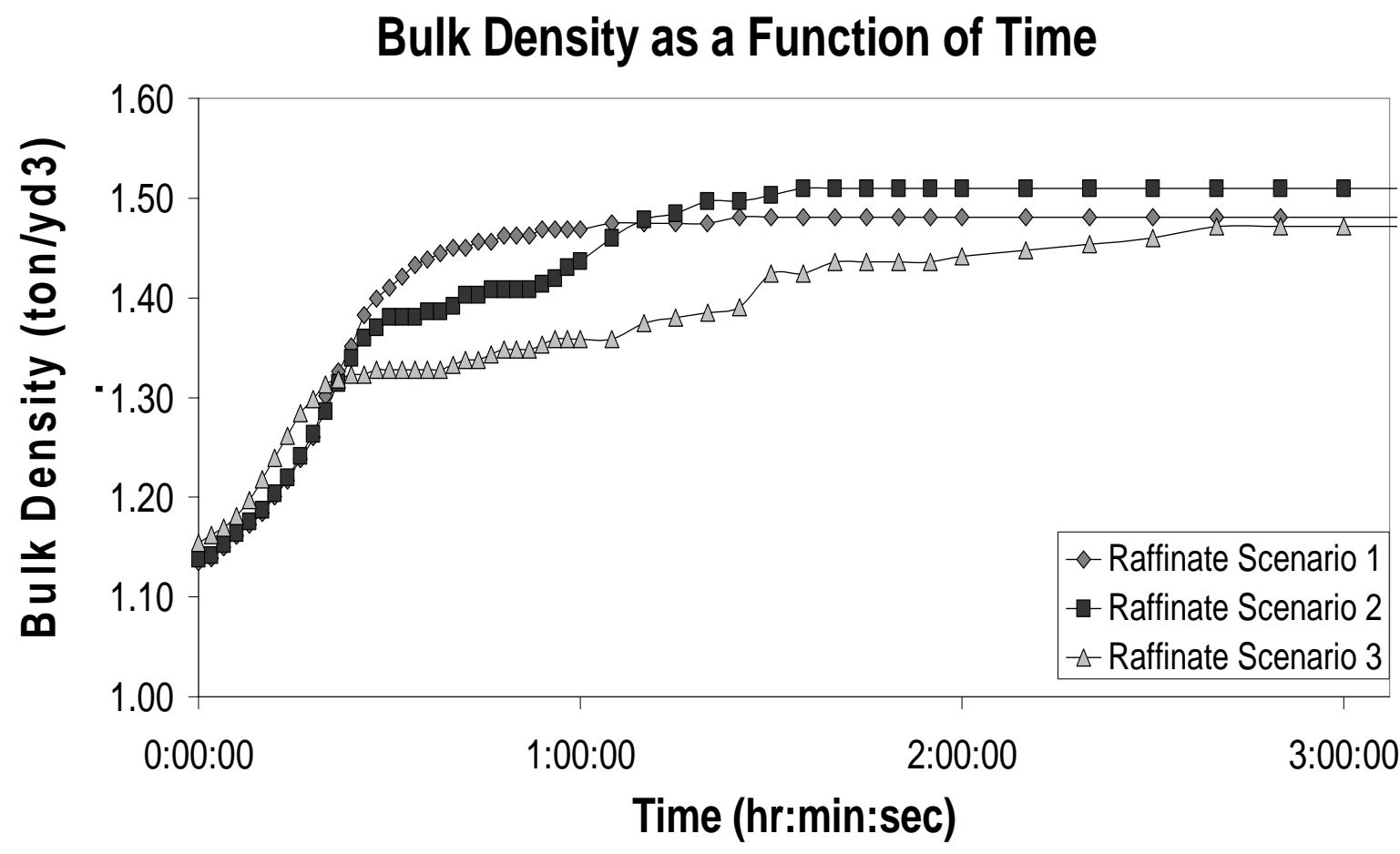

Figure 34: This graph illustrates the bulk density as a function of time for the columns containing raffinate only agglomerated samples. Three different paths exist but lead to a similar overall bulk density.

Scenario 1 had an ideal bulk density change over time curve. This scenario yielded the highest hydraulic conductivity of the raffinate trials for the first eight hours of the test. While comparing the raffinate trials, several points of significance were determined. In scenario 1 the ore in the column began wetting as expected. Fines migration could be seen occurring in the column as the solution wetted. At 28 minutes into the test, the solution in the overflow tube could be seen rising slowly and then dropping rapidly. This surging suggested pressure would build and then drop in the ore bed. At 42 minutes, the solution level in the column was above the compression piston and air bubbles were released from the ore bed corresponding to a drop of solution height in the overflow tube. 
This continued until the ore become completely wetted at 58 minutes. The void spaces in the ore bed that still remained were filled with air until the end of the test. The measurable fines migration percentage was $0.43 \%$ for this scenario.

Scenario 2 resulted in a non-ideal curve of bulk density change over time. This scenario yielded the second highest hydraulic conductivity of the raffinate trials for the first 8 hours of the test. During the atypical part of the curve, the pressure within the column surged as solution slowly wetted the remainder of the ore. The column became completed wetted after 68 minutes into the test.

Scenario 3 has a non-ideal curve of bulk density change over time. This scenario yielded the worst hydraulic conductivity of the three trials for the first 8 hours of the test. Scenario 3 is quite different than either of the first two scenarios. The ore did not become completely wetted until 230 minutes into the test.

What occurred in this column, during scenario 3, was an interesting phenomenon. The fines migration had effectively sealed off a portion of the column from downward solution flow. The result was the creation of a dead spot. The dead spot can be seen in Figure 35, as well as the great amount of hydraulic head that had built up above the ore. 


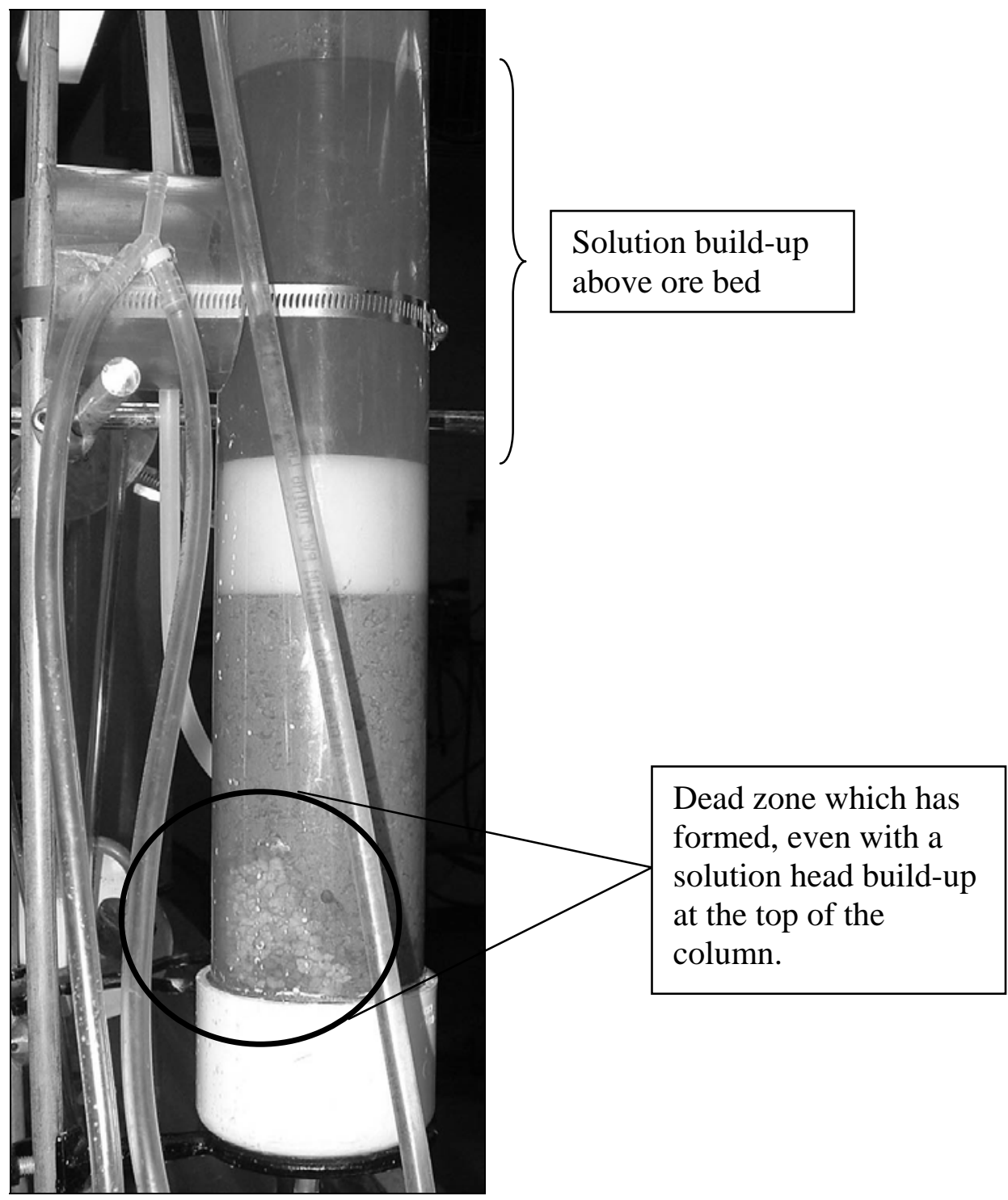

Figure 35: This photograph shows the ponding effects due to fines migration in scenario 3. A large amount of solution can be seen in the column above the ore and the overflow break over point (the $\mathrm{Y}$ fitting at the upper left corner).

After 24 hours, the area remained saturated with solution. However, the fines had not migrated because there was no appreciative solution flow. This corresponds to the measurable migration of fines being $0.30 \%$ which is less than the consistent $0.43 \%$ the other two columns yielded. With no appreciative solution flow, the time it would take for any reaction to occur and the solubilized copper to migrate back to the higher flow area would be extensive. This would result in a longer leach cycle or a loss of recovery.

The addition of a binder in agglomeration helped to decrease the bulk density of the system resulting in better solution flows. Figure 36 indicates that the use of the binders resulted in lower bulk densities than the average column agglomerated with raffinate. This signified that there was less of a breakdown of the agglomerates with time with the use of a binder. 


\section{Bulk Density Comparison}

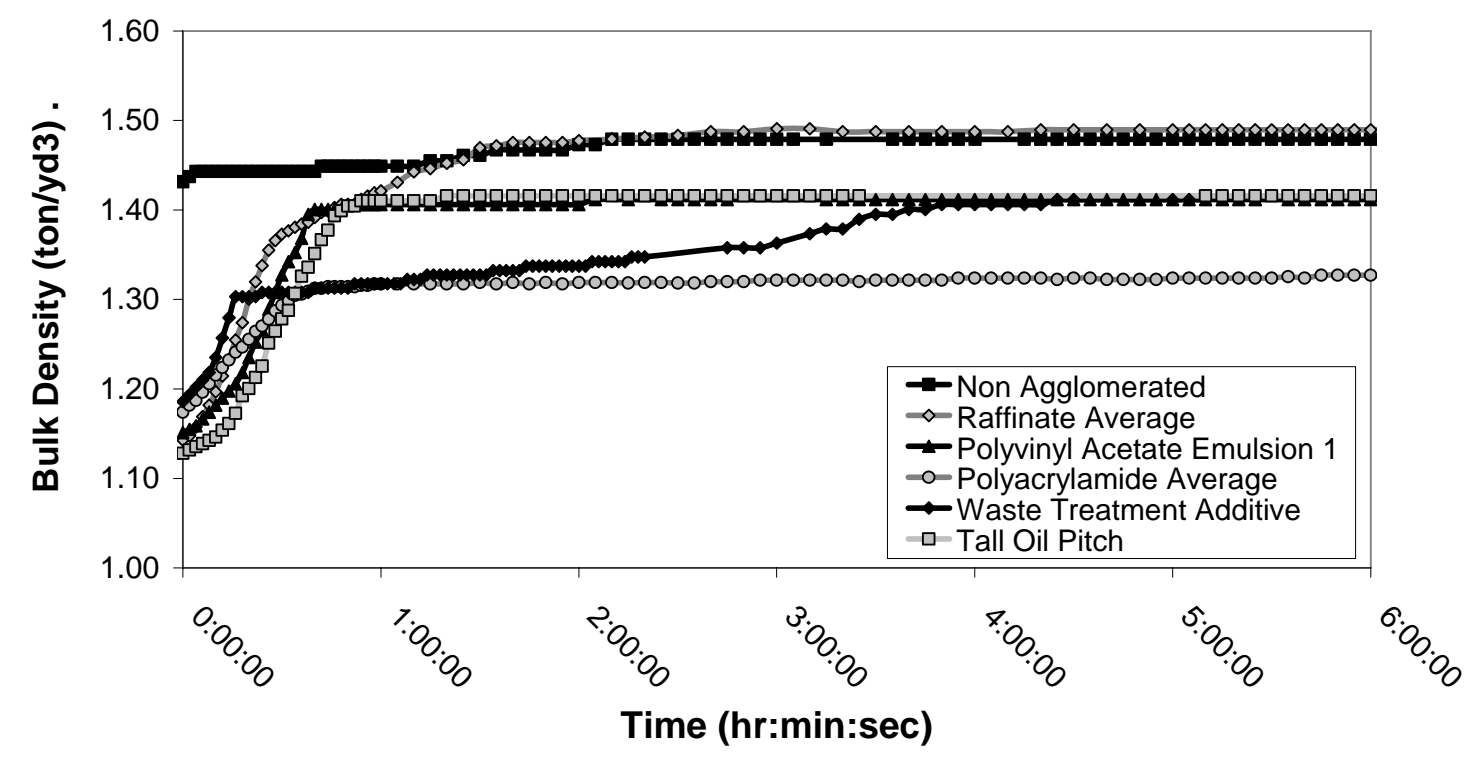

Figure 36: This graph illustrates the bulk density as a function of time for the columns containing raffinate and for the columns containing ore agglomerated with various binders. These results indicate that the use of a binder helped to decrease the bulk density, which will lead to an increase in solution flow.

The addition of a binder in agglomeration helped to increase the hydraulic conductivity, the ability for solution to flow within the heap, compared to using raffinate alone as a binder. These results are shown in Figure 37. The polyacrylamide had the lowest bulk density, along with the highest hydraulic conductivity. This leads to the conclusion that the lower the bulk density, the greater the availability for solution to flow through the heap. 


\section{Hydraulic Conductivity Comparison}

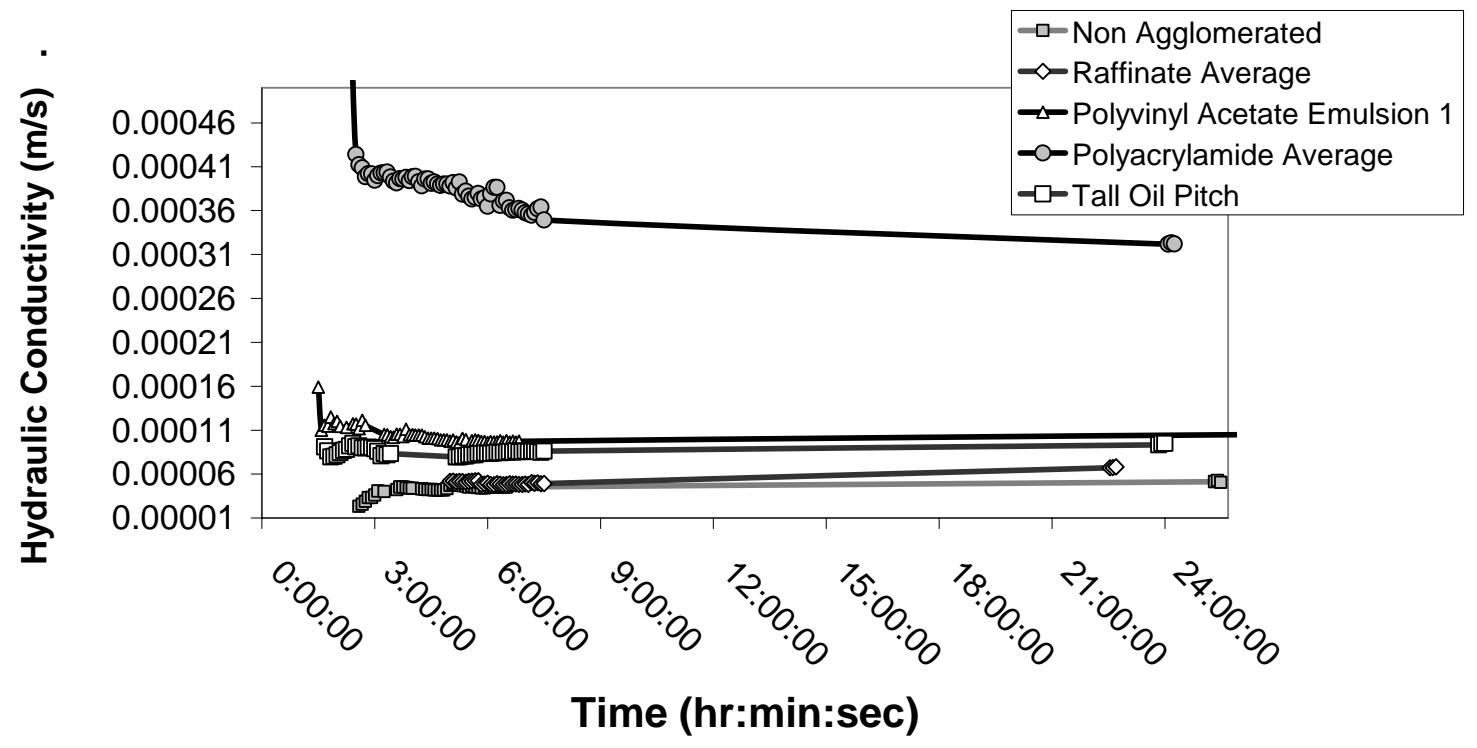

Figure 37: This graph illustrates the hydraulic conductivity as a function of time for the columns containing raffinate and for the columns containing ore agglomerated with various binders. These results indicate that the use of a binder helped to increase the hydraulic conductivity, which indicates an increase in solution flow.

These results indicated that under compaction, the use of a binder helps to increase the strength of the agglomerates when compared to using raffinate alone. This was shown by a decrease in bulk density, meaning that fine particles from the agglomerates were not breaking off. It was also shown by an increase in hydraulic conductivity, the ease of solution flow. The use of the binders resulted in the solution having an easier time flowing through the ore bed. This will lead to the availability for better contact between the solution and the ore, ending in better copper recovery rates.

A scale up of the compression apparatus has been constructed. This is also a specially designed apparatus which falls under the provisional patent, serial number US60/750,236, held by the investigators of this project at Michigan Technological University. This scaled up column will allow copper recoveries to be determined at various compaction levels within the heap. This apparatus will hopefully bring to light various conditions which have been discovered in the flooded column compaction test, and there influence on copper recovery. In the future, multiple columns could be conjoined to simulate and entire heap within the laboratory setting. 


\section{Economic Analysis}

The polyacrylamide had consistently performed well throughout the various testing procedures including, soak tests, percolation tests, long-term leach columns, and compaction testing. It was necessary to determine whether the use of this product would be economical on an industrial scale.

It was determined that at the current copper selling price of approximately $\$ 3.00$ per pound of copper, the use of the polyacrylamide could be justified by only a $2-4 \%$ increase in copper recovery from the heap or by a comparable decrease in the length of the leach cycle. This increase in copper recovery was based off of the price quoted from the manufacturer, if the polyacrylamide was used at a dosage rate of $1 \mathrm{lb} /$ ton of ore. However, if the dosage rate was able to be dropped to $0.5 \mathrm{lb} / \mathrm{ton}$, the use of the product could be justified with only a $1-2 \%$ increase in copper recovery from the heap or again by a comparable decrease in the length of the leach cycle.

The polyacrylamide also offers the benefit of leaving process equipment free of residue during agglomeration. This would help eliminate the clogging of chutes which currently occurs, and results in downtime in the operation. This type of benefit along with others, have not been included in the current economic evaluation of the polyacrylamide product. This evaluation was completed using a base cost for the product only. It does not include installation, application equipment, storage, etc.

\section{Summary}

Permeability is a problem in copper leach heaps. This permeability problem is due to the buildup of fine particles in the spaces between the larger particles. The build-up of particles results in poor solution flow and in turn decreased metal recovery rates. Agglomeration helps to eliminate the problem of fine material by adhering particles together. However, the use of a binder will help to increase the benefits of agglomeration by adding additional strength to the agglomerates. It will help to increase recovery rates which improve energy efficiency.

A wide variety of binder choices were available including inorganic, organic, and polymer binders. Although, there were no standard tests in place which would determine which binder type would be beneficial. The soak test was developed to determine which binder would be able to hold together in the acidic environment of a heap. The polymer binders, mainly non-ionic and slightly cationic binders, were able to withstand the acidic environment which would be experienced in a leach heap.

The flooded column test was designed to assess the binders' ability to allow solution to flow through the ore bed. All the binders tested showed an increase in solution flow over using raffinate as a binder. The use of the binders also maintained void space in the ore bed better than the raffinate agglomerated ore. These factors are important, as the ability for the solution to come in contact with the ore is critical for good metal recovery rates. 
The effect of the binder on copper recovery rates was able to be analyzed by the design and construction of the long-term leach columns. These columns subjected the agglomerated ore to an environment which simulated a leach heap as closely to its actual performance as is possible at that point in time. A meeting was held with our industrial partners, after a review of the results and experimental procedures accomplished. Both MTU and the Arizona location decided to concurrently run six long-term leach columns. The duplicate columns were able to be used to show that the long-term leach column results were reproducible. They also helped determine whether our industrial partners would progress with additional larger scale test work. The six long-term leach columns have shown that the use of the binders does not have any negative effects on the copper recovery.

The long-term leach columns are able to simulate the heap by scale down factors; however, they are unable to simulate factors such as compaction due to the weight of the ore in the heap. Therefore, a compaction leach column has been designed, constructed, and patented to assess the performance of the binders on solution flow and void space within a compacted heap. The results of these tests have shown there is a tremendous difference in the behavior of compacted ore verses non compacted ore. A large increase in the evenness of solution flow was discovered. This experimental procedure also brought to light other factors, such as channeling, which occur in an ore bed under compaction. A larger scale compaction column is also falls under the provisional patent held by the MTU investigators. This column will help determine the effect of the binders on copper recovery with compaction conditions similar to what would be occurring further down in the heap.

\section{Conclusions}

The use of agglomeration in copper heap leaching has been found to increase the rate at which the metal can be recovered. However, they are still not as high as desired. Increasing copper recovery in heap leaching by the use of binders and agglomeration would result in a significant decrease in the amount of energy consumed. Assuming that $70 \%$ of all the leaching heaps would convert to using agglomeration technology, as much as $1.64 * 10^{12}$ BTU per year would be able to be saved if a $25 \%$ increase in copper recovery was experienced. This is the equivalent to saving approximately $18 \%$ of the energy currently being used in leaching heaps. Even if the copper recovery may not be able to be increased, the desired recovery may be achieved but with a shortened leach period. Shortening the leach cycle of a heap leach one week allows for total energy savings of $1.23 * 10^{11}$ BTU/Week assuming $70 \%$ of the leach heaps implements the technology. Achieving increased copper recovery along with a decrease in leach time will only amplify the energy saving results expected from either one of these alone.

The use of a binder in addition to agglomeration will help to allow for better solution flow through an ore bed and result in increased copper recovery rates. Previously, there were no standard tests developed to determine which types of binders will perform best. 
A binder needs to be able to not break down in an acidic environment, allow for good solution flow, and not inhibit copper recovery.

Several tests have been developed which allow each binder to be analyzed, to determine which types of binders will result in improved copper recovery rates. Overall, polymer binders have been found to have the greatest strength when used in agglomerates and subjected to an acidic environment. The binders help to increase solution flow and maintain void space which results in better contact of the leach solution, air, and ore. The use of these binders also has not adversely affected copper recovery. The use of polyacrylamide, in particular, has shown improved results in comparison to using raffinate alone in agglomeration, especially under compacted conditions. An economic analysis of this product showed that only a small increase in heap recovery, or a decrease in the leach cycle, would justify the use of this product. Any additional recovery, or benefits of this product, would only add to the profit resulting from the heap. Constant communication with our industrial partners has allowed concurrent testing to be done at MTU and at a copper leach facility in Arizona. Meetings with the industrial partners to discuss MTU's results have allowed possible future testing to be considered. 


\section{References}

Aplan, F.F., (1995) 'A Modest Proposal for Improving Recovery from Gold \& Silver Heap-Leaching Operations’, Engineering \& Mining Journal, Vol. 196, No. 5, pp. 52-53

Bartlett, R. W., (1997) 'Metal extraction from ores by Heap Leaching', Metallurgical and Materials Transactions B, v.28B no.4, pp. 529-545.

Brierley, C.L., Brierley J.A., (1999) 'Copper Bioleaching: State-of-the-Art', Proceedings of the Copper 1999 International Conference - Volume IV: Hydrometallurgy of Copper, Oct. 10-13, 1999, Phoenix, pp. 59-68, The Minerals, Metals \& Materials Society, Warrendale, PA.

Casas, J.M., et al., (1998) 'Bioleaching Model of a Copper-Sulfide Ore Bed in Heap and Dump Configurations’, Metallurgical and Materials Transactions B, v.29B, pp. 899-909.

Chamberlin, P. D., (1986) “Agglomeration: Cheap Insurance for Good Recovery when Heap Leaching Gold and Silver Ores”, Mining Engineering, Vol. 38, No. 12, pp. 11051109

Dixon, D., (2003) 'Heap Leach Modeling - The Current State of the Art', Hydrometallurgy 2003 - 5th International Conference - Volume 1: Leaching \& Solution Purification, Aug. 24-27, 2003, Vancouver, pp. 289-314, TMS, Warrendale, PA.

Efthymiou, M. et al., (1998) 'Practical Aspects of the Application of Extract-Ore 9560 for Heap Leach Agglomeration at Nifty Copper Operation', ALTA Copper Hydrometallurgy Forum, Oct. 20-21, 1998, Queensland, Australia, pp.1-15

Eisele, J.A. et al., (1984) 'Recovery of Gold and Silver from Ores by Hydrometallurgical Processing', Separation Science and Technology, Vol. 18, No. 12 \& 13, pp. 1081-1094

Eisele, J. A., and Pool, D. L., (1987) “Agglomeration Heap Leaching of Precious Metals” CIM Bulletin, Vo. 80, No. 902, pp. 31-4

Eisele, T.C., et al., (2005) "Determination of Acid Resistance of Agglomerates in Copper Heap Leaching”, Presented at the 2005 Society for Mining, Metallurgy, and Mining Exploration (SME) Annual Meeting \& Exhibit, Feb.28-Mar.2, 2005, Salt Lake City, pp. 1-11

Ferron, C.J., (2003) 'Leaching of Secondary Copper Minerals using Regenerated Ferric Sulphate', Proceedings of the Copper 2003 - The 5th International Conference - Volume VI: Leaching and Process Development, Nov.30-Dec.3, 2003, Santiago, pp. 337-352, Canadian Institute of Mining, Metallurgy and Petroleum, Montreal, Quebec, Canada 
GE Infrastructure - Water \& Process Technologies (2004) Applications in Copper Heap Leaching [on-line], Trevose, PA. Available from:

http://www.gewater.com/pdf/Bulletin968EN.pdf (Accessed July 2005)

Gross, A. E., and Strominger, M. G., "Development of a Polymeric Agglomeration Aid for Heap Leaching”, Innovations in Gold and Silver Recovery, Chapter 28, pp. 5775-5795

Hiskey, J.B., (1986) 'Technical Innovations Spur Resurgence of Copper Solution Mining', Mining Engineering, Vol. 38, No. 11, pp. 1036 - 1039

Lewandowski, K.A., et al., (2006) "Determination of Acid Resistance of Copper Ore Agglomerates in Heap Leaching”, To be Presented at the 2006 Sohn International Symposium on Advanced Processing of Metals and Materials: Principles, Technologies and Industrial Practice, Aug. 27-31, 2006, San Diego, pp. 1-18

McClelland, G.E. et al., U.S. Dept. of the Interior - Bureau of Mines, (1985)

'Agglomeration and Heap Leaching of Finely Ground Precious-Metal-Bearing Tailings', Bureau of Mines Information Circular 9034

McClelland, G. E., (1986) "Agglomerated and Unagglomerated Heap Leaching Behavior is Compared in Production Heaps”, Mining Engineering, Vol. 38, No. 7, pp 500-503.

Petersen, J., Dixon, D.G., (2003) 'The Dynamics of Chalcocite Heap Bioleaching', Hydrometallurgy 2003 - Fifth International Conference in Honor of Professor Ian Ritchie - Volume I: Leaching and Solution Purification, Aug. 24-27, 2003, Vancouver, pp. 351-365, TMS, Warrendale, PA

Pietsch, W., (2002) Agglomeration Processes, Weinheim, Wiley-VCH Verlag GmbH, pp.614

Polizzotti, D.M. et al., (1999) 'Polymeric Agglomerating Agents for the Gold Mining Industry', $3^{\text {rd }}$ UBS-McGill International Symposium on Fundamentals of Mineral Processing, August 22-25, 1999, Hamilton, Ontario, Canada, pp. 455-462, Metallurgical Society, Montreal, Quebec, Canada

Rumpf, H., Engl. Ed.: Ball, F.A. (Translator) (1990) Particle Technology, London, U.K., Chapman \& Hall

Uhrie, J.L. et al., (2003) 'The metallurgical development of the Morenci MFL project', Proceedings of the Copper 2003 - The 5th International Conference - Volume VI:

Leaching and Process Development, Nov.30-Dec.3, 2003, Santiago, pp. 29-37, Canadian Institute of Mining, Metallurgy and Petroleum, Montreal, Quebec, Canada.

U.S. Dept. of Energy - Office of Energy Efficiency and Renewable Energy, (2004) Novel Binders and Methods for Agglomeration of Ore [online], Washington, DC. Available 
from: http://www.eere.energy.gov/industry/mining/pdfs/novelbinders.pdf (Accessed July 2005)

U.S.G.S. Minerals Yearbook Year 2000, (2006) Copper Statistics and Information [online], Reston, VA, Available from:

http://minerals.usgs.gov/minerals/pubs/commodity/copper/ (Accessed June 2006)

von Michaelis, H., (1992) Innovations in Gold \& Silver Recovery Chapter 28, Golden, CO, Randol International Ltd., pp. 5775-5794.

Weir, D.R., (1984) 'Some Recent Developments in Hydrometallurgy', Canadian Metallurgical Quarterly, Vol. 23, No. 4, pp. 353-363 